\title{
Chrna5-Expressing Neurons in the Interpeduncular Nucleus Mediate Aversion Primed by Prior Stimulation or Nicotine
} Exposure

\author{
Q Glenn Morton, ${ }^{1}$ Nailyam Nasirova, ${ }^{1}$ Daniel W. Sparks, ${ }^{3}$ Matthew Brodsky, ${ }^{1}$ Sanghavy Sivakumaran, ${ }^{3}$ \\ -Evelyn K. Lambe, ${ }^{3,4,5}$ and $\odot$ Eric E. Turner ${ }^{1,2}$ \\ ${ }^{1}$ Center for Integrative Brain Research, Seattle Children's Research Institute, ${ }^{2}$ Department of Psychiatry and Behavioral Sciences, University of Washington, \\ Seattle, Washington 98101, ${ }^{3}$ Department of Physiology, ${ }^{4}$ Department of Obstetrics and Gynecology, and ${ }^{5}$ Department of Psychiatry, University of Toronto, \\ Toronto, Ontario M5S 1A8, Canada
}

Genetic studies have shown an association between smoking and variation at the CHRNA5/A3/B4 gene locus encoding the $\alpha 5, \alpha 3$, and $\beta 4$ nicotinic receptor subunits. The $\alpha 5$ receptor has been specifically implicated because smoking-associated haplotypes contain a coding variant in the CHRNA5 gene. The Chrna5/a3/b4 locus is conserved in rodents and the restricted expression of these subunits suggests neural pathways through which the reinforcing and aversive properties of nicotine may be mediated. Here, we show that, in the interpeduncular nucleus (IP), the site of the highest Chrna 5 mRNA expression in rodents, electrophysiological responses to nicotinic acetylcholine receptor stimulation are markedly reduced in $\alpha 5$-null mice. IP neurons differ markedly from their upstream ventral medial habenula cholinergic partners, which appear unaltered by loss of $\alpha 5$. To probe the functional role of $\alpha 5$-containing IP neurons, we used BAC recombineering to generate transgenic mice expressing Cre-recombinase from the Chrna5 locus. Reporter expression driven by Chrna $5{ }^{\text {Cre }}$ demonstrates that transcription of Chrna 5 is regulated independently from the Chrna3/b4 genes transcribed on the opposite strand. Chrna5-expressing IP neurons are GABAergic and project to distant targets in the mesopontine raphe and tegmentum rather than forming local circuits. Optogenetic stimulation of Chrna5-expressing IP neurons failed to elicit physical manifestations of withdrawal. However, after recent prior stimulation or exposure to nicotine, IP stimulation becomes aversive. These results using mice of both sexes support the idea that the risk allele of CHRNA5 may increase the drive to smoke via loss of IP-mediated nicotine aversion.

Key words: acetylcholine; chrna5; habenula; interpeduncular nucleus; nicotine; optogenetics

Significance Statement

Understanding the receptors and neural pathways underlying the reinforcing and aversive effects of nicotine may suggest new treatments for tobacco addiction. Part of the individual variability in smoking is associated with specific forms of the $\alpha 5$ nicotinic receptor subunit gene. Here, we show that deletion of the $\alpha 5$ subunit in mice markedly reduces the cellular response to nicotine and acetylcholine in the interpeduncular nucleus (IP). Stimulation of $\alpha 5$-expressing IP neurons using optogenetics is aversive, but this effect requires priming by recent prior stimulation or exposure to nicotine. These results support the idea that the smokingassociated variant of the $\alpha 5$ gene may increase the drive to smoke via loss of IP-mediated nicotine aversion.

\section{Introduction}

Nicotine is a powerfully addictive drug, but under specific conditions of dosage and prior exposure, nicotine consumption can

Received Jan. 4, 2018; revised June 8, 2018; accepted June 15, 2018.

Author contributions: G.M., D.W.S., E.K.L., and E.E.T. wrote the first draft of the paper; G.M., N.N., E.K.L., and E.E.T. edited the paper; E.K.L. and E.E.T. designed research; G.M., N.N., D.W.S., M.B., and S.S. performed research; G.M., N.N., D.W.S., M.B., S.S., E.K.L., and E.E.T. analyzed data; E.E.T. wrote the paper.

This work was supported by the National Institutes of Health (Grant R01-DA035838 to E.E.T. and Grant R01MN093667 to E.E.T.), the Canadian Institutes of Health Research (Grant MOP-89825 to E.K.L.), a Canada Research Chair in Developmental Cortical Physiology (E.K.L.), and the Alzheimer's Society Research Program of Canada (Postdoctoral Fellowship to D.W.S.). The parent BAC construct used to generate $\mathrm{Chrna5}{ }^{\mathrm{Cre}}$ transgenic mice was generated be either reinforcing or aversive. Understanding the variety of nicotinic receptors ( $\mathrm{nAChRs}$ ) that mediate these effects and the

by the Gene Expression Nervous System Atlas (GENSAT) Project supported by National Institute of Neurological Disorders and Stroke Contracts N01NS02331 and HHSN271200723701C to The Rockefeller University. AAV-DIOsypEGFP was generously provided by Julie Harris, Karla Hirokawa, and Hong Gu of the Allen Institute for Brain Science. We thank Mariella De Biasi for the original gift of $\alpha 5^{\mathrm{K} 0}$ mice, Julie Harris and Hongkui Zeng of the Allen Institute for Brain Science for access to unpublished data, and Lely Quina and Janice McNabb for expert technical assistance.

Correspondence should be addressed to Eric E. Turner, Seattle Children's Research Institute, University of Washington, 1900 Ninth Avenue, Mail Stop C9S-10, Seattle, WA 98101. E-mail: eric.turner@seattlechildrens.org.

D0I:10.1523/JNEUROSCI.0023-18.2018

Copyright $\odot 2018$ the authors $\quad 0270-6474 / 18 / 386900-21 \$ 15.00 / 0$ 
neural pathways that express these receptors is of key importance for understanding the mechanisms and genetics of nicotine addiction and for the design of new medications to treat this disorder. The strongest known genetic risk for increased tobacco consumption is associated with certain haplotypes at the Chrna5/ $a 3 / b 4$ gene locus that occur at high frequency in European populations (Berrettini and Doyle, 2012; Lassi et al., 2016). These high-risk haplotypes contain a nonsynonymous Chrna5 polymorphism, Chrna5(D398N), which appears to reduce the function of $\alpha 4 \beta 2$-containing $\left(\alpha 4 \beta 2^{\star}\right)$ and $\alpha 3 \beta 4^{\star}$ nicotinic receptors into which the risk-associated $398 \mathrm{~N}$ variant is incorporated (Kuryatov et al., 2011; George et al., 2012; Tammimäki et al., 2012; Morel et al., 2014; Sciaccaluga et al., 2015; Koukouli et al., 2017).

The Chrna5/a3/b4 gene locus is conserved between humans and rodents and the tissue-specific expression of the receptors encoded by these genes suggests neural pathways of importance in nicotine addiction (Picciotto and Mineur, 2014). The channelforming $\alpha 3$ and $\beta 4$ receptor subunits are prominently expressed in the ventral medial habenula $(\mathrm{MHbV})$ and the accessory $\alpha 5$ receptor subunit is highly expressed in the interpeduncular nucleus (IP) that receives MHbV input (Marks et al., 1992; Salas et al., 2003; Hsu et al., 2013). The $\alpha 5$ subunit is also detected in the ventral tegmental area (VTA), where it regulates striatal nicotine effects (Exley et al., 2012), and in deep layers of the cerebral cortex, where loss of $\alpha 5$ may impair performance in attentional tests (Bailey et al., 2010). Genetic studies have shown that mice lacking the $\alpha 5$ subunit ( $\alpha 5^{\mathrm{KO}}$ mice) have attenuated somatic signs of nicotine withdrawal (Jackson et al., 2008; Salas et al., 2009) and show self-administration and place preference with high doses of nicotine that are usually aversive (Jackson et al., 2010; Fowler et al., 2011; Morel et al., 2014).

Pharmacological studies also support a role for the $\mathrm{MHbV}$ and/or IP as mediating behavioral responses to nicotine, including reinforcement, aversion, and withdrawal (Salas et al., 2009; Zhao-Shea et al., 2013, 2015; Antolin-Fontes et al., 2015; Harrington et al., 2016), but are not by themselves sufficient to assess the role of the $\alpha 5$ subunit, which does not participate in the usual ligand binding site of $\mathrm{nAChRs}$ and thus has no specific agonist or antagonist. Here, we show that the IP neurons of $\alpha 5^{\mathrm{KO}}$ mice have a markedly attenuated physiological response to acetylcholine and nicotine, making the IP a strong candidate for mediating some of the behavioral effects of this nicotinic receptor subunit. We did not observe an attenuation in the nicotine response of MHbV neurons in $\alpha 5^{\mathrm{KO}}$ mice despite the prevailing idea that $\alpha 5$ expression is relevant to MHb function (Fowler et al., 2011; Frahm et al., 2011; Fowler and Kenny, 2014; Antolin-Fontes et al., 2015).

Prior studies have addressed $\alpha 5$ function in mice using BAC transgenic methods to manipulate the Chrna5/a3/b4 locus (Frahm et al., 2011; Hsu et al., 2013). However, this approach may misexpress the other genes in the $\alpha 5$ cluster, which can independently affect physiology and behavior. Here, we have used a $\mathrm{BAC}$ recombineering strategy to produce a new Chrna $5^{\mathrm{Cre}}$ transgenic line to manipulate $\alpha 5$-expressing neurons without misexpression artifacts. Reporter expression driven by Chrna5 ${ }^{\text {Cre }}$ shows that Chrna5 transcription is independently regulated from the Chrna3/b4 genes transcribed on the opposite strand. Chrna ${ }^{\mathrm{Cre}}$-expressing neurons in the rostral IP (IPR) are GABAergic, but project to specific areas of the mesopontine raphe rather than forming local circuits within the IP. Optogenetic stimulation of $\alpha 5$-expressing IP neurons is aversive, but only after recent prior stimulation or exposure to a single dose of nicotine. Therefore, the activation of neurons expressing $\alpha 5^{\star}$ receptors in different brain regions may govern the overall rewarding or aversive response to nicotine.

\section{Materials and Methods}

Animals. Mice bearing a deletion of the Chrna5 gene have been described previously (Salas et al., 2003) and have been backcrossed to C57BL/6 (Charles River Laboratories) for $>10$ generations. Mice null for $\alpha 5$ $\left(\alpha 5^{\mathrm{KO}}\right.$ mice) were generated from crosses of heterozygous $\left(\alpha 5^{+/-}\right)$ mice. To express channelrhodopsin (ChR2-YFP) in the MHbV of $\alpha 5^{\mathrm{KO}}$ and control mice, ChAT-ChR2 mice (ChAT-ChR2-YFP BAC; Jax \#014546; Zhao et al., 2011) expressing channelrhodopsin in ChATpositive cholinergic neurons were first interbred with $\alpha 5^{\mathrm{KO}}$ mice to produce compound heterozygotes. Mice with the $\alpha 5^{+/-} /$ChAT-ChR2 genotype were then bred to $\alpha 5^{+/-}$mice to produce mice heterozygous for ChAT-ChR2 and either $\alpha 5 \mathrm{WT}\left(\alpha 5^{+/+}\right.$, control) or $\alpha 5^{\mathrm{KO}}$ for electrophysiological experiments. To confirm that the expression of ChATChR2 did not alter the basal firing properties of $\mathrm{MHbV}$ neurons, we replicated the findings from $\mathrm{ChR} 2$ mice in tonically firing $\mathrm{MHbV}$ neurons of mice arising from the original $\alpha 5^{+/-}$cross that did not express ChR2.

Three independent lines of Chrna $5^{\text {BACCre }}$ mice, hereafter referred to as Chrna5 ${ }^{\text {Cre }}$ mice, were generated by oocyte injection of a modified Chrna5/a3/b4 BAC, as described in the Results. The parent BAC containing Cre recombinase targeted to the Chrna5 locus was generated as part of the GENSAT project (Gong et al., 2003; Gerfen et al., 2013) and obtained from the BACPAC Resources Center, Children's Hospital Oakland Research Institute. The transgene encompassed $\sim 50 \mathrm{~kb}$ of genomic sequence spanning chr9:54,809,614-54,859,149 of the mouse genome (NCBI version 37 ) and extending from $\sim 19 \mathrm{~kb}$ upstream from the Chrna5 translation start site to $\sim 3.5 \mathrm{~kb}$ beyond the $3^{\prime}$ terminus of the Chrna5 transcribed region adjacent to the $3^{\prime}$ terminus of the Chrna3 transcript, which is transcribed on the opposite strand. The Cre expression cassette was inserted immediately after the initial ATG of the Chrna5 open reading frame at chr9:54,828,904. Recombineering of the parent Gensat BAC-Cre construct and oocyte injections were performed by Cyagen Biosciences. We resequenced all the relevant parts of the BAC transgenic construct to confirm the complete removal of the Chrna3 and Chrnb4 open reading frames and also to confirm that the original GENSAT modification of the Chrna5 locus with the insertion of the Cre cassette were all correct. Because the Chrna ${ }^{\mathrm{Cre}}$ transgene contains no transcribed sequences from the Chrna3 or Chrnb4 loci, there is no direct mechanism by it can affect the expression levels of the endogenous Chrna5/a3/b4 genes. In addition, because the Chrna $5{ }^{\mathrm{Cre}}$ transgene is not integrated at the Chrna5/a3/b4 gene locus, cis-acting regulatory sequences contained within the BAC transgene will only affect the expression of the Cre transgene, not the endogenous genes. Three male founder transgenic mice were characterized by breeding with the reporter strain Ai6 (below). After the initial characterization of reporter gene expression, a single Chrna 5 Cre transgenic line ("line 3 ") was used for all subsequent experiments.

Somatostatin (SST)-expressing neurons were identified using the SSTIRES-Cre targeted transgenic strain, Sst ${ }^{\text {tm2.1(cre)Zjh/J }}$ (Jackson Laboratories, catalog \#013044), which has been described previously (Taniguchi et al., 2011). Three Cre-inducible reporter strains, all targeted to the Gt(ROSA)26Sor locus, were used: Ai6 and Ai14 were used as Credependent fluorescent reporters for the genetic identification of cell phenotypes; Ai6 (B6.Cg-Gt(ROSA)26Sortm6(CAG-ZsGreen1)Hze/J, Jax 007906) expressing a ZsGreen reporter and Ai14 (B6.Cg-Gt(ROSA) 26Sortm14(CAG-tdTomato)Hze/J, Jax 007914) expressing a cytoplasmic tdTomato reporter, have been described previously (Madisen et al., 2010). Mice for Cre-driven optogenetic studies were generated using the mouse line Ai32 (B6.Cg-Gt(ROSA)26Sortm32(CAG-COP4H134R/EYFP)Hze/J, Jax 024109), which conditionally expresses the Channelrhodopsin-2 variant ChR2(H134R)-EYFP (Madisen et al., 2012). Mice bearing a Chrna5 ${ }^{\text {Cre }}$ allele and an Ai32 allele were used all in vivo optogenetic experiments and are referred to as $\mathrm{IP}^{\mathrm{ChR} 2}$ mice. All transgenic lines used in behavioral experiments were maintained on a C57BL/6 genetic background (Charles River Laboratories). Chrna5 ${ }^{\mathrm{Cre}}$ mice were backcrossed at least 
three generations and Ai32 mice at least six generations with commercially supplied C57BL/6 mice before use in behavioral experiments. Experiments using $\alpha 5^{\mathrm{KO}}$ or $\alpha 5^{\mathrm{KO}} / \mathrm{ChAT}$-ChR2 mice and matched controls were performed under the guidelines of the Canadian Council on Animal Care and all experimental procedures were approved by the Faculty of Medicine Animal Care Committee at the University of Toronto. Experimental procedures in Chrna $5{ }^{\mathrm{Cre}}$ mice, inducible reporter lines, and controls were approved by the Institutional Animal Care and Use Committee of Seattle Children's Research Institute.

Electrophysiology methods. Acute brain slice electrophysiology experiments in littermate WT $\left(\alpha 5^{+/+}\right)$and homozygous knock-out $\left(\alpha 5^{\mathrm{KO}}\right)$ mice were performed to assess the significance of $\alpha 5$ subunit expression on neurophysiological activity and cholinergic modulation of neurons in the IPR and the MHbV. Experiments included recordings from $12 \mathrm{WT}$ mice and $13 \alpha 5^{\mathrm{KO}}$ mice. Coronal slices of brain tissue including the IPR or the $\mathrm{MHbV}$ were obtained by investigators blinded to genotype from male and female adult mice (mean \pm SEM, postnatal day $121 \pm 9$ ).

Mice were anesthetized with chloral hydrate $(400 \mathrm{mg} / \mathrm{kg})$ and decapitated and their brains quickly removed and chilled in $4^{\circ} \mathrm{C}$ sucrose ACSF containing the following (in $\mathrm{mm}$ ): 254 sucrose, 10 D-glucose, 24 $\mathrm{NaHCO}_{3}, 2 \mathrm{CaCl}_{2}, 2 \mathrm{MgSO}_{4}, 3 \mathrm{KCl}$, and $1.25 \mathrm{NaH}_{2} \mathrm{PO}_{4}, \mathrm{pH}$ 7.4. Coronal brain slices ( $\sim$ bregma -3.5 for the IPR, $\sim$ bregma $1.0-2.0$ for the $\mathrm{MHbV}$ ), $400 \mu \mathrm{M}$ thick, were obtained using a Dosaka linear slicer (Sci Media) and recovered for $\sim 2 \mathrm{~h}$ in regular ACSF containing the following (in mM): $128 \mathrm{NaCl}, 10 \mathrm{D}$-glucose, $26 \mathrm{NaHCO}_{3}, 2 \mathrm{CaCl}_{2}, 2 \mathrm{MgSO}_{4} 4,3 \mathrm{KCl}$, and $1.25 \mathrm{NaH}_{2} \mathrm{PO}_{4}, \mathrm{pH}$ 7.4. All solutions were oxygenated with $95 \%$ $\mathrm{O}_{2} / 5 \% \mathrm{CO}_{2}$.

For whole-cell electrophysiological recordings, brain slices containing the IPR or MHbV were placed in a perfusion chamber on the stage of a BX50W1 microscope (Olympus) and perfused with oxygenated ACSF at a rate of $3-4 \mathrm{ml} / \mathrm{min}$. Recording electrodes $(2.5-4.5 \mathrm{M} \Omega$ ) were filled with solution containing the following (in $\mathrm{mM}$ ): 120 potassium gluconate, 5 $\mathrm{KCl}, 2 \mathrm{MgCl}_{2}, 4 \mathrm{~K}_{2}$-ATP, $0.4 \mathrm{Na}_{2}$-GTP, $10 \mathrm{Na}_{2}$-phosphocreatine, and 10 HEPES buffer, with $\mathrm{pH}$ adjusted to 7.3 using $\mathrm{KOH}$. Data were acquired at $20 \mathrm{kHz}$, low-pass filtered at $3 \mathrm{kHz}$ using pClamp software (Molecular Devices), and corrected for the liquid junction potential (14 mV). ChATChR2-positive MHbV cells, which send cholinergic projections to GABAergic cells in the IP (Ren et al., 2011; Hsu et al., 2013), were identified visually using YFP fluorescence and patched in either hemisphere. Confirmation of neuronal identity was obtained both by observing the characteristic tonic firing at rest and confirming the presence of ChR2 using $473 \mathrm{~nm}$ blue light stimulation ( $5 \mathrm{~ms}$ pulse delivered while holding the neuron at $-75 \mathrm{mV}$ in voltage clamp). No differences were found in these light-evoked current responses between genotypes (WT, $604 \pm 40$ $\left.\mathrm{pA}, \mathrm{N}=14, \mathrm{a} 5^{\mathrm{KO}}, 528 \pm 81 \mathrm{pA}, \mathrm{N}=13, t_{(25)}=0.86, p=0.4\right)$.

To examine the electrophysiological impact of Chrna5 subunit expression in the IPR, we assessed the effects of bath application of ACh (acetylcholine chloride, Sigma-Aldrich; $100 \mu \mathrm{M}$ to $1 \mathrm{~mm}, 15 \mathrm{~s}$ ) and nicotine (nicotine hydrogen tartrate salt, Sigma-Aldrich; $1 \mu \mathrm{M}, 60 \mathrm{~s}$ ) on the amplitude of current responses using voltage-clamp recordings with neurons held at $-75 \mathrm{mV}$. Rapid bath application $(3-4 \mathrm{ml} / \mathrm{min})$ was selected to survey receptors in a location-unbiased manner that would mimic the arrival of nicotine in the brain, which happens on a time course of seconds (Rose et al., 2010). However, we note that this approach may underestimate a rapidly desensitizing response. The role of synaptic transmission in mediating cholinergic response amplitude was assessed using the AMPA receptor antagonist CNQX (Tocris Bioscience; $20 \mu \mathrm{M}$ ), the NMDA receptor antagonist APV (D-2-amino-5-phosphonovaleric acid, Sigma-Aldrich; $50 \mu \mathrm{M}$ ), and the $\mathrm{GABA}_{\mathrm{A}}$ receptor antagonist bicuculline (bicuculline methiodide, Tocris Bioscience; $10 \mu \mathrm{M}$ ). We also assessed the role of the $\alpha 4 \beta 2^{\star}$ nicotinic ACh receptor in cholinergic current responses using dihydro- $\beta$-erythroidine hydrobromide ( $\mathrm{DH} \beta \mathrm{E}$, SigmaAldrich; $10 \mu \mathrm{M}$ ). To assess the role of Chrna5 subunit expression on nicotinic responses in the MHbV and IPR, bath application of nicotine was delivered during current-clamp recordings from resting membrane potential (MHbV) or from $-70 \mathrm{mV}$ (MHbV and IP).

All electrophysiological data are expressed as the mean \pm SEM. Parametric or nonparametric statistical tests were used according to the Shapiro-Wilk test of normality. Intrinsic electrophysiological properties of
WT and $\alpha 5^{\mathrm{KO}}$ neurons, as well as current responses to light stimulation in MHbV ChAT-ChR2 neurons, were compared using independent $t$ tests. Concentration response data were assessed using two-way ANOVA. Differences in responses to cholinergic and nicotinic stimulation between WT and $\alpha 5^{\mathrm{KO}}$ neurons were assessed using Mann-Whitney nonparametric $t$ tests. Differences in cholinergic responses before and after application of synaptic blockers or $\mathrm{DH} \beta \mathrm{E}$ were assessed using Wilcoxon matched-pairs signed-rank nonparametric tests.

Methods used for measuring light-evoked action potentials in acute brain slices from adult mice have been described previously (Hsu et al., 2013). Neurons expressing ChR2-EYFP were identified visually in brain slices of IP ${ }^{\text {ChR2 }}$ mice aged 2-4 months by their endogenous fluorescence. Recordings were performed on a total of 8 adult $\mathrm{IP}^{\mathrm{ChR} 2}$ mice. Glass pipettes (3-7 M $\Omega$ ) filled with intracellular pipette solution containing the following (in $\mathrm{mm}$ ): $140 \mathrm{~K}$-gluconate acid, $1 \mathrm{CaCl}_{2}, 2 \mathrm{MgSO}_{4}, 10$ EGTA, 4 Na2-ATP, 0.3 Na-GTP, and 10 HEPES, pH 7.2, were used for all recordings. The recording bath solution consisted of aCSF containing the following (in mM): $118 \mathrm{NaCl}, 3 \mathrm{KCl}, 25 \mathrm{NaHCO}_{3}, 1 \mathrm{NaH}_{2} \mathrm{PO}_{4}, 1 \mathrm{MgCl}_{2}$, $1.5 \mathrm{CaCl}_{2}$, and 30 glucose, $\mathrm{pH} 7.4$, with added GABA blockers gabazine $(10 \mu \mathrm{M})$ and $2-\mathrm{OH}$ saclofen $(50 \mu \mathrm{M})$ in all recordings. Light pulses (10 $\mathrm{ms}$ ) were delivered from a $473 \mathrm{~nm}$ blue laser coupled to an optical fiber positioned in the recording bath $2 \mathrm{~mm}$ form the recording pipette tip, producing $1-2 \mathrm{~mW} / \mathrm{mm}^{2}$ irradiance at the recording pipette tip. When possible, we measured the baseline firing of the cell and the light response of the cell to $5,10,20$, and $50 \mathrm{~Hz}$ light pulses using cell-attached recording, followed by recording the response of the cell in current-clamp mode.

Tract tracing, immunofluorescence, and FISH. For Cre-dependent labeling of cell bodies and axons, we used AAV1-CAG.Flex.tdTomato. WPRE.bGH (Addgene Plasmid \#51503) or AAV1-CAG.Flex.EGFP. WPRE.bGH (Addgene Plasmid \#51502, Oh et al., 2014), Viral stocks were prepared at the University of Pennsylvania Gene Therapy Program Vector Core (http://www.med.upenn.edu/gtp/vectorcore/). Enhanced labeling of the terminal fields of neuronal projections was performed by Cre-dependent viral expression of a synaptophysin-EGFP fusion protein (sypGFP). The plasmid pCAG.Flex.SypEGFP.WPRE (AAV-sypGFP) was constructed by replacing the EGFP moiety of pCAG-FLEX-EGFP-WPRE with the sypGFP construct from phSyn1(S)-FLEX-tdTomato-T2A-SypEGFPWPRE (Addgene Plasmid \#51509) by Julie Harris, Karla Hirokawa, and Hong Gu of the Allen Institute for Brain Science. In most experiments, the tdTomato axonal tracer and the sypGFP synaptic tracer viruses were coinjected.

The detailed methods used here for anterograde tract tracing with iontophoretic injection of AAV have recently been published in conjunction with the Allen Mouse Brain Connectivity Atlas (Harris et al., 2012; Oh et al., 2014). The injection coordinates used were as follows: Case IP-a1: AP 3.5 (from bregma), ML 0.1, DV 4.6; Case MnR-a1: AP 4.3, ML 0.2, DV 4.2; Case MnR-a2: AP 4.1, ML 0.3, DV 4.5; based on a standard atlas (Paxinos and Franklin, 2001). Animals were fixed by transcardial perfusion with $4 \%$ paraformaldehyde at $14-21 \mathrm{~d}$ after injection, brains were removed and equilibrated in graded sucrose solutions, frozen at $-80^{\circ} \mathrm{C}$ in optimal cutting temperature solution, and cryosectioned at 25 $\mu \mathrm{m}$ for fluorescence/immunofluorescence imaging (Quina et al., 2017). Antisera used and references for the validation of their specificity include: Gpr151 C-terminus, rabbit polyclonal, Sigma-Aldrich SAB4500418, RRID:AB_10743815 (Broms et al., 2015); green fluorescent protein (GFP), goat polyclonal, Abcam ab6673, RRID:AB_305643; choline acetyltransferase (ChAT), goat polyclonal, Millipore AB144P, RRID: AB_2079751; substance $P$, rat monoclonal IgG2a, EMD Millipore MAB356, RRID:AB_94639; Somatostatin (S-14), rabbit polyclonal, Peninsula Laboratories T-4103, RRID:AB_518614; tryptophan hydroxylase 2 (Tph2), rabbit polyclonal, Millipore ABN60, rabbit polyclonal, RRID: AB_10806898; and cFos, rabbit polyclonal, Santa Cruz Biotechnology Sc-52, RRID:AB_2106783.

Double-label FISH (DFISH) was performed as part of the Allen Institute for Brain Science transgenic characterization project (Oh et al., 2014). Complete datasets used for expression Chrna5 + TH mRNA, used here to show Chrna5 expression alone (experiment 304864931), and 
Chrna5 + Gad1 mRNA (experiment 127833597) are available online at: http://connectivity.brain-map.org/transgenic.

Behavioral tests. Three cohorts of mice were used for behavioral studies. All behavioral cohorts consisted of Chrna5 ${ }^{\mathrm{Cre}}, \mathrm{Gt}(\mathrm{ROSA}) 26 \mathrm{Sor}{ }^{\mathrm{Ai32} /+}$ experimental mice (IP ${ }^{\mathrm{ChR} 2}$ ), and Gt(ROSA)26Sor ${ }^{\mathrm{Aiz2} /+}$ controls lacking the Cre driver from the same or simultaneously generated litters. Cohort 1 consisted of 6 male and 6 female experimental mice, and 4 male and 4 female control mice. Cohort 2 consisted of 3 male and 4 female experimental mice, and 3 male and 7 female control mice. Cohort 3 consisted of 6 male and 6 female experimental mice, and 8 male and 7 female control mice. All mice were between 2 and 3 months old at the time of surgery and between 3 and 6 months old at the time of the behavioral experiments. Cohort 1 underwent open-field locomotion, stimulus-primed real-time place preference (RTPP), and intracranial self-stimulation (ICSS). Cohort 2 underwent the light/dark box test, RTPP, RTPP controls with no light stimulus on day 2 of the protocol and priming of the response by light stimulus in the home cage, and testing for somatic signs of nicotine withdrawal. Cohort 3 underwent RTPP, RTPP control for priming of the response by light stimulus in the home cage, and priming of the RTPP response by acute administration of nicotine.

Mice were implanted with a $100 \mu \mathrm{m}$ (cohorts 1 and 3) or $200 \mu \mathrm{m}$ (cohort 2) fiber-optic cannula targeting the IP using a $20^{\circ}$ angle and the target stereotaxic coordinates AP -3.3 to -3.5 ( $\mathrm{mm}$ caudal to bregma), ML 0.00 (midline), and DV 4.60 (Paxinos and Franklin, 2001). After the behavioral experiments, mice were perfused with $4 \%$ paraformaldehyde and the brains of all subject animals were examined for ChR2-EYFP fluorescence in the IP to confirm the genotype and the consistent expression of the transgene and for cannula placement. Although some cannulas differed slightly from the intended coordinates, only one animal from cohort 1 and one animal from cohort 3 were excluded from the behavioral analysis due to a misplaced cannula; in these cases, the cannula had obstructed the cerebral aqueduct, causing hydrocephalus. Behavioral data are presented graphically as mean \pm SEM.

Open-field locomotion. Open-field locomotion was assessed in IP ChR2 and control mice over three 10 min intervals: baseline, stimulation, and poststimulation. The stimulation period consisted of $30 \mathrm{~s}$ periods of $20 \mathrm{~Hz}$ light pulses alternating with $30 \mathrm{~s}$ periods of light off. The open-field test enclosure consisted of a $27.3 \mathrm{~cm} \times 27.3 \mathrm{~cm}$ arena (ENV-510, Med Associates) housed in a sound attenuating chamber (ENV-018MD, Med Associates). For determination of time spent in the center and periphery of the enclosure, a center area of $17.5 \times 17.5 \mathrm{~cm}$ was defined in the video image. The total distance traveled was analyzed using the video-tracking software EthoVision XT 10.0 (Noldus Information Technology).

Light/dark box. Studies were conducted in a three-chamber placepreference box (ENV-3013, Med Associates). Incident light on the dark side of the chamber was blocked by covering it with black felt. Light intensity on the light side of the chamber was $\sim 750$ lux and the black side was $\sim 2$ lux. The $473 \mathrm{~nm}$ laser delivered $10 \mathrm{~ms}$ pulses at $20 \mathrm{~Hz}$ and $8 \mathrm{~mW}$ power to all subjects for the duration of the $15 \mathrm{~min}$ trial. Time spent in the dark chamber was measured for all subjects and compared between genotypes using unpaired $t$ tests.

Video recording for the open-field test, RTPP test, and light/dark box test was performed with an ICD-49 B/W video camera with heliopan E35.5 RG 850 IR lens filter (Ikegami Tsushinki) under IR Illumination. In all experiments recorded with Noldus Ethovision, an Arduino UNO microprocessor was used to control the frequency and pulse duration of a $473 \mathrm{~nm}$ modulated laser diode (MLD, model 0473-06-01-0100-100, Cobolt) to deliver light pulses via a fiber-optic cannula.

Somatic signs associated with nicotine withdrawal. To reproduce the methods used in prior work, somatic signs typically associated with nicotine withdrawal were assessed using a previously described optogenetic stimulation protocol (Zhao-Shea et al., 2013). Behaviors were assessed in a standard housing cage and animals were acclimated to the test cage for $45 \mathrm{~min} / \mathrm{d}$ on the $2 \mathrm{~d}$ before the test. Experiments were performed in nicotine-naive mice. Optogenetic stimulation at $8 \mathrm{~mW}$ was delivered intermittently to the IP for $10 \mathrm{~min}$, followed by $10 \mathrm{~min}$ of recording without stimulation. The stimulation consisted of repeated $50 \mathrm{~Hz}, 0.2 \mathrm{~s}$ trains of $5 \mathrm{~ms}$ pulses ( 10 pulses) delivered at $1 \mathrm{~s}$ intervals for $5 \mathrm{~s}$, followed by lights-off periods of $5 \mathrm{~s}$. Mice were video recorded throughout the 20 min trial and the entire period was scored manually by two independent raters who were blinded to genotype. Six somatic signs associated with withdrawal were scored: scratching, head or body shaking ("like a wet dog"), head nodding (at least two closely consecutive nods), backing (both hind limbs must step backward), rearing (on side or in middle of cage, both forepaws must leave bedding), and chewing. The average scores of two independent scorers blinded to genotype were used for each behavior and subject and the effect of genotype was assessed using unpaired $t$ tests, with subsequent correction for multiple hypothesis testing.

ICSS. To test ICSS reinforcement by IP stimulation, mice were placed into an operant chamber (ENV-307W, Med Associates) with two response wheels that record one event for every $90^{\circ}$ of rotation (ENV113AMW, Med Associates). One response wheel was randomly assigned as the active wheel in the initial four $45 \mathrm{~min}$ trials and reversed for the second four trials. Two turning events recorded on the active wheel within a $2 \mathrm{~s}$ interval resulted in the delivery of $2 \mathrm{~s}$ of $473 \mathrm{~nm}$ light stimulation consisting of $10 \mathrm{~ms}$ pulses delivered at $20 \mathrm{~Hz}$ and $8 \mathrm{~mW}$ power.

RTPP. RTPP studies were conducted in a two-chamber placepreference box (ENV-010MC, Med Associates) in which mice received light stimulation on one side and could move freely between compartments. The 15 min sessions were initiated by placing the mouse in the center of the apparatus. For each subject, the active side was randomly assigned in the initial trial and reversed in each subsequent trial. Recording and laser stimulation were controlled with EthoVision XT using center point tracking. The active chamber was paired with a $473 \mathrm{~nm}$ laser that was activated, delivering $10 \mathrm{~ms}$ light pulses at a $20 \mathrm{~Hz}$ and $8 \mathrm{~mW}$ of total power, until the mouse crossed over to the inactive chamber, whereas no simulation was delivered in the inactive chamber. Active and inactive chamber occupancy and total distance traveled were then calculated for each $5 \mathrm{~min}$ interval of the $15 \mathrm{~min}$ session and for the entire session. In the standard RTPP experiments, two trials were performed on consecutive days, differing only by the reversal of the stimulated side. Two variants of the RTPP protocol were performed as controls. In one variant, one side of the chamber was stimulated on day 1 and no stimulus was present on day 2. In another variant, intermittent stimulation was provided for $15 \mathrm{~min}$ in a standard housing cage on day 1 and day 2 was conducted in the two-compartment chamber. To administer light stimulation in a standard housing cage, the stimulation intervals were pseudorandomized based on the typical distribution of stimulation periods delivered to control mice in the two compartment box, with a total stimulation time of $7.5 \mathrm{~min}$ ( $50 \%$ of trial). An identical $15 \mathrm{~min}$ intermittent stimulation protocol was used to induce the expression of cFos in the $\mathrm{IP}$ of IP ${ }^{\mathrm{ChR} 2}$ mice ( $n=3 \mathrm{IP} \mathrm{ChR}^{\mathrm{C} 2}$ mice, 3 cannulated controls). In the cFos induction trials, mice were acclimated to the test cage for $5 \mathrm{~d}$ before testing. Mice were perfused with paraformaldehyde $2 \mathrm{~h}$ after the end of the stimulation period.

Acute administration of nicotine and nicotine inhibition of home cage locomotion. To assess the effects of nicotine on home cage locomotion and RTPP, mice were administered $0.3 \mathrm{mg} / \mathrm{kg}$ nicotine ditartrate subcutaneously and returned to a standard housing enclosure. Nicotine dosage was calculated based on the mass of the free base and administered as a $0.1 \mathrm{mg} / \mathrm{ml}$ solution (Bailey et al., 2010). Distance traveled was then recorded for 1-16 min after injection using Noldus Ethovision center point tracking. Two hours after injection, mice were placed in the twocompartment place-preference enclosure for a 15 min RTPP trial with optogenetic stimulation of the IP, as described above. The test was repeated using the same methods $10 \mathrm{~d}$ later. Due to the short half-life of nicotine in mouse plasma ( $<10 \mathrm{~min}$; Siu and Tyndale, 2007), the timing of the locomotor test represents the acute effect of nicotine and the RTPP trial tests the effect of recent exposure to nicotine. Reversal trials in the nicotine-primed RTPP study were conducted on day 10 of the experiment to avoid any effect of activity-primed aversion.

\section{Results}

\section{Electrophysiology of the IP response to ACh and nicotine}

To address directly the significance of the expression of the Chrna5 subunit in the rostral interpeduncular nucleus, we performed acute slice recordings from sibling WT $\left(\alpha 5^{+/+}\right)$and 
Table 1. Electrophysiological properties of neurons in the IPR in brain slices from WT and $\alpha 5{ }^{\mathrm{K} 0}$ mice

$\begin{array}{lllll}R_{\mathrm{m}}(\mathrm{M} \Omega) & \mathrm{RMP}(\mathrm{mV}) \quad C_{\mathrm{m}}(\mathrm{pF}) & \text { Spike amplitude }(\mathrm{mV}) & \text { Spike threshold }(\mathrm{mV})\end{array}$

$\begin{array}{llllll}\text { WT } & 321 \pm 35 & -73 \pm 2 & 63 \pm 8 & 42 \pm 3 & -40 \pm 3\end{array}$

$\alpha 5^{\mathrm{K} 0} \quad 386 \pm 43 \quad-69 \pm 2 \quad 69 \pm 7 \quad 48 \pm 3 \quad-43 \pm 2$

Intrinsic neuronal properties illustrated are input resistance $\left(R_{\mathrm{m}}\right)$, resting membrane potential (RMP), capacitance $\left(C_{\mathrm{m}}\right)$, spike amplitude, and spike threshold. WT, $n=27$ neurons from 5 mice; $\alpha 5^{\mathrm{K} 0}, n=33$ neurons from 5 mice. Data are shown as mean \pm SEM.

$\alpha 5^{\mathrm{KO}}$ mice. The intrinsic properties of IPR neurons were recorded and compared by genotype (Table 1 ). There were no significant differences on measures of input resistance, resting membrane potential, capacitance, spike amplitude, or spike threshold.

We first investigated how the absence of Chrna5 subunit expression affected current response to bath application of ACh (1 $\mathrm{mm})$. Data for both the WT and $\alpha 5^{\mathrm{KO}}$ groups failed the ShapiroWilk test for normality (WT, $n=27, W=0.75, p<0.0001$; $\alpha 5^{\mathrm{KO}}, n=27, W=0.72, p<0.0001$, Fig. $1-1$, available at https:// doi.org/10.1523/JNEUROSCI.0023-18.2018.f1-1 relating to Fig. $1)$, necessitating the use of nonparametric analyses. The amplitude of current responses was markedly reduced in a ${ }^{\mathrm{KO}}$ IP neurons (WT, $227 \pm 50 \mathrm{pA}, n=27 ; \alpha 5^{\mathrm{KO}}, 37 \pm 7 \mathrm{pA}, n=27$, Mann-Whitney $U=70.0, p<0.0001$; Fig. $1 A, B)$ and this genotype difference was observed across a range of concentrations (100 $\mu \mathrm{M}$ to $1 \mathrm{mM}$; WT, $n=8 ; \alpha 5^{\mathrm{KO}} n=6 ; F_{1,34}=16.6, p=$ 0.0003; Fig. $1 C, D)$.

IP neurons are predominantly GABAergic and receive synaptic inputs from the MHbV that are both glutamatergic and cholinergic (Ren et al., 2011; Hsu et al., 2013). The MHbV terminals are rich in nAChRs that could act presynaptically to facilitate glutamate release. In the presence of synaptic blockers (APV, CNQX, and bicuculline), there was a significant reduction in the current amplitude of responses to ACh in within-cell experiments (WT baseline, $252 \pm 75$, synaptic blockers, $147 \pm 52 \mathrm{pA}$, $n=9 ; \alpha 5^{\mathrm{KO}}$ baseline, $41 \pm 11$, synaptic blockers, $19 \pm 5 \mathrm{pA}, n=$ 6; Wilcoxon $W=-110.0, p=0.006$, data not shown). However, in the presence of synaptic blockers, there remains a strong and significant genotype difference in cholinergic currents (WT: $147 \pm 52 \mathrm{pA}, n=9 ; \alpha 5^{\mathrm{KO}}: 18 \pm 5 \mathrm{pA}, n=6$; Mann-Whitney $U=$ 4.0, $p=0.005$; Fig. $1 E, F)$. This demonstrates that glutamatergic synaptic transmission contributes to the ACh response of IP neurons, but their intrinsic response to ACh is strongly affected by the presence of the $\alpha 5$ subunit.

To determine the principal subtype of channel-forming nAChRs mediating the cholinergic response in the IPR and thus potentially associated with $\alpha 5$ subunits in this nucleus, we blocked ACh-induced currents with the $\beta 2^{\star} \mathrm{nAChR}$ antagonist $\mathrm{DH} \beta \mathrm{E}(10 \mu \mathrm{M}, 10 \mathrm{~min})$. Cholinergic currents were substantially reduced by $\mathrm{DH} \beta \mathrm{E}$ in both genotypes (WT: baseline, $360 \pm 143$; $\mathrm{DH} \beta \mathrm{E}, 75 \pm 25 \mathrm{pA} ; n=5 ; \alpha 5^{\mathrm{KO}}$ : baseline, $44 \pm 14 ; \mathrm{DH} \beta \mathrm{E}, 8 \pm$ 3 pA; $n=4$; Wilcoxon $W=-45.0 p=0.004$; Fig. $1 G, H)$.

Because the current responses to ACh application were largely mediated by nAChRs, we next applied nicotine $(1 \mu \mathrm{M})$ in the bath to assess differences in response between genotypes. Inward currents elicited by nicotine were significantly greater in WT neurons (WT, $122 \pm 35 \mathrm{pA}, n=14 ; \alpha 5^{\mathrm{KO}}, 16 \pm 4 \mathrm{pA}, n=12$; Mann-Whitney $U=31.0, p=0.005$; Fig. $1 I, J)$. These results indicate that the Chrna5 gene is critical for the normal response of IPR neurons to nicotinic stimulation.

\section{Contrasting nicotine-induced excitability of WT and $\alpha 5^{\mathrm{KO}}$ neurons in the IP and MHbV}

To investigate the question of where $\alpha 5$ exerts its maximal effects within the habenula-IP pathway, we examined the ability of nicotine to excite IP neurons and MHbV cholinergic neurons in adult WT and $\alpha 5^{\mathrm{KO}}$ mice (Fig. 2). Nicotine (1 $\left.\mu \mathrm{M}\right)$ was bath applied to WT and $\alpha 5^{\mathrm{KO}}$ neurons in the IPR in current-clamp conditions (Fig. 2A). The peak nicotine-elicited spike frequency was greater in neurons from WT $(13.8 \pm 5 \mathrm{~Hz}, n=15)$ than $\alpha 5^{\mathrm{KO}}$ mice $(1.6 \pm 1 \mathrm{~Hz}, n=12$, Mann-Whitney $U=46.0, p=0.02$; Fig. 2B-D; data failed the Shapiro-Wilk test for normality, necessitating the use of non-parametric analyses, see Fig. 2-1, available at https://doi.org/10.1523/JNEUROSCI.0023-18.2018.f2-1.). Voltageclamp recordings confirmed the significant difference in nicotinic currents observed above (WT, $144.9 \pm 50 \mathrm{pA}, n=7, \alpha 5^{\mathrm{KO}}, 14.5 \pm$ 9 pA, $n=12$, Mann-Whitney $U=3.0, p<0.001)$. Membrane and action potential properties did not differ significantly between genotypes except for greater input resistance in the $\alpha 5^{\mathrm{KO}}$ neurons in this sample (WT, $348 \pm 90 \mathrm{M} \Omega, n=8, \alpha 5^{\mathrm{KO}}, 812 \pm 164 \mathrm{M} \Omega$, MannWhitney $U=18, p=0.03$ ), which would suggest that they were IP cells of a type that would otherwise have the most prominent responses to nicotine (Shih et al., 2014).

Because cholinergic neurons in the $\mathrm{MHbV}$ are the vital part of the habenula-IP pathway, we also tested the response of these neurons to nicotine. We recorded from the tonically firing, YFPpositive ChAT-ChR2 neurons in the MHbV of either hemisphere (Fig. 2E,F) and confirmed the presence of ChR2 (see Materials and Methods) in both WT and a ${ }^{\mathrm{KO}}$ transgenic mice. Intrinsic properties of $\mathrm{MHbV}$ neurons were measured and compared by genotype and no significant differences between genotypes were found on any measures (Table 2). In the first set of experiments, nicotine $(1 \mu \mathrm{M})$ was applied while neurons were firing tonically at rest in current clamp, increasing their firing frequency (Fig. $2 F$ ). In contrast to the IP recordings, however, peak nicotine-elicited firing frequency did not differ significantly between $\mathrm{MHbV}$ neurons from WT $(9.3 \pm 1.4 \mathrm{~Hz}, n=12)$ and $\alpha 5^{\mathrm{KO}}(7.9 \pm 1.4 \mathrm{~Hz}$, $n=13$ ) mice (Mann-Whitney $U=58.0, p=0.29$; Fig. $2 F-H$ ). To avoid a potential ceiling effect, we next assessed nicotineinduced firing in current clamp from an initial membrane potential of $-70 \mathrm{mV}$, similar to the starting membrane potential in the IP experiments. Nicotine depolarized $\mathrm{MHbV}$ cholinergic neurons, as illustrated in Figure 2I, yet no difference was found in nicotine-elicited peak firing frequency between genotypes (WT, $4.3 \pm 0.8 \mathrm{~Hz}, n=12, \alpha 5^{\mathrm{KO}}, 3.4 \pm 1.1 \mathrm{~Hz}, n=12$, Mann-Whitney $U=49.0, p=0.19$; Fig. $2 I-K)$. Additional voltage-clamp experiments with neurons held at $-75 \mathrm{mV}$ did not detect any significant difference in the response to nicotine between genotypes $\left(\mathrm{WT}, 20.6 \pm 5 \mathrm{pA}, n=12, \alpha 5^{\mathrm{KO}}, 15.0 \pm 3.8 \mathrm{pA}, n=11\right.$, MannWhitney $U=52.5, p=0.4$ ). In a final series of experiments, we recorded from nonlabeled, tonically firing neurons in the $\mathrm{MHbV}$ of WT and $a 5^{\mathrm{KO}}$ mice from the original a $5^{+/-}$cross. In these $\mathrm{MHbV}$ neurons recorded at rest, nicotine-elicited peak firing frequencies also did not differ significantly between genotype (WT, $9.2 \pm 1.6 \mathrm{~Hz}, n=12, \alpha 5^{\mathrm{KO}}, 11.9 \pm 1.2 \mathrm{~Hz}, n=5$, Mann-Whitney $U=20.5, p=0.3$ ), nor were there significant differences in $\mathrm{MHbV}$ membrane properties between genotypes (data not shown).

\section{Generation and characterization of Chrna5 ${ }^{\text {Cre }}$ transgenic mice}

The cell-specific expression of the $\alpha 5 / \alpha 3 / \beta 4 \mathrm{nAChRs}$ determines the possible repertoire of pentameric receptors in a given neuron and thus the function of these receptors in specific brain regions. 
A

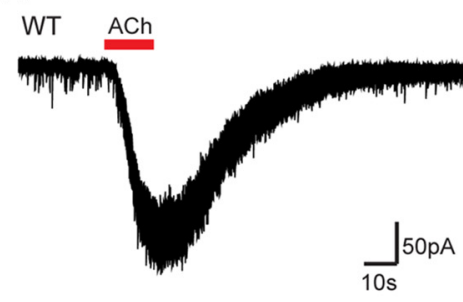

a5 KO ACh

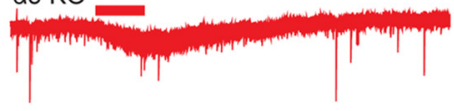

B

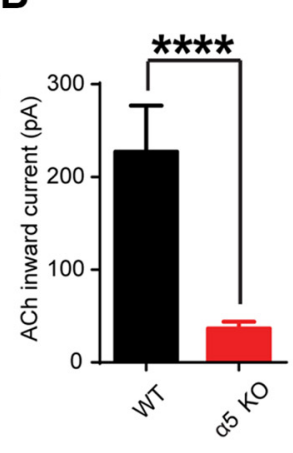

C

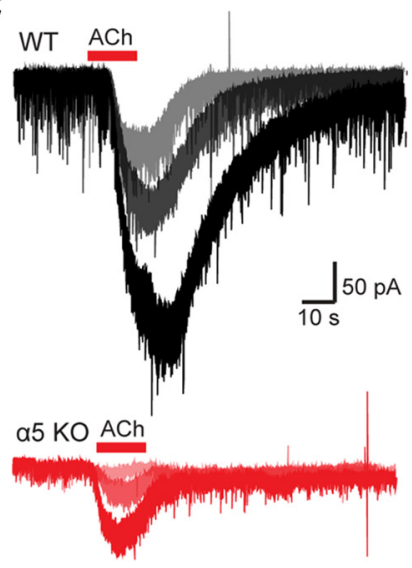

G

F

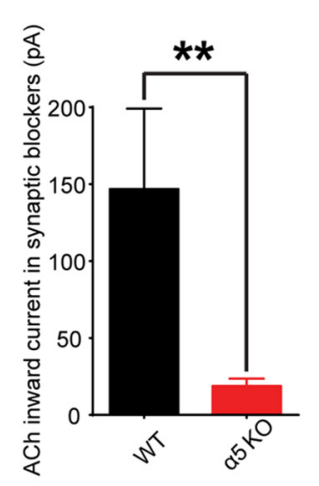

D

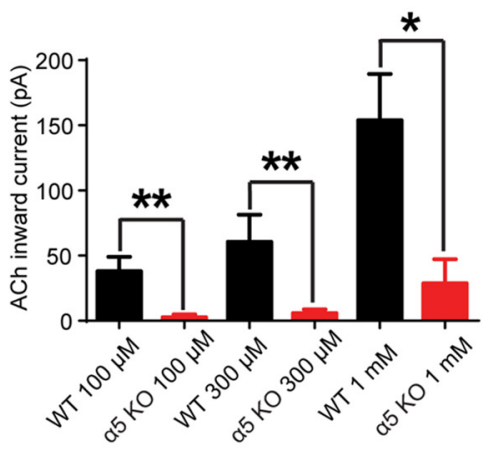

H

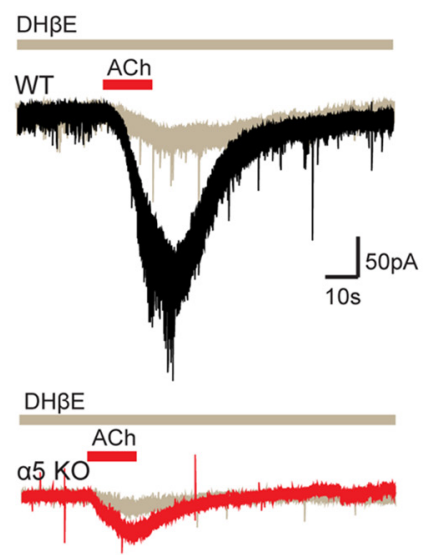

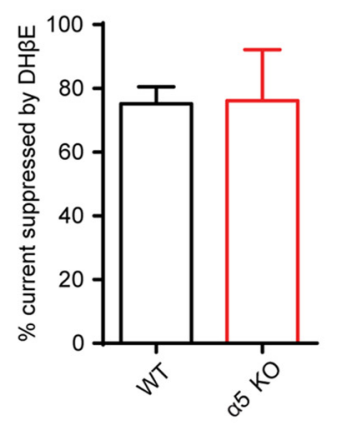

E

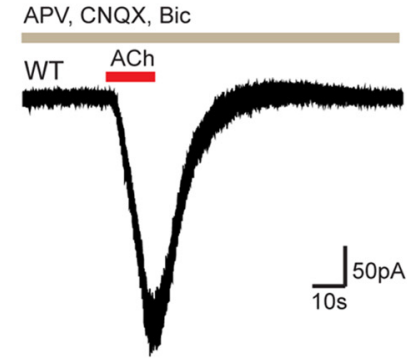

APV, CNQX, Bic

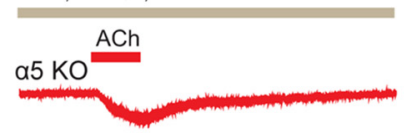

I

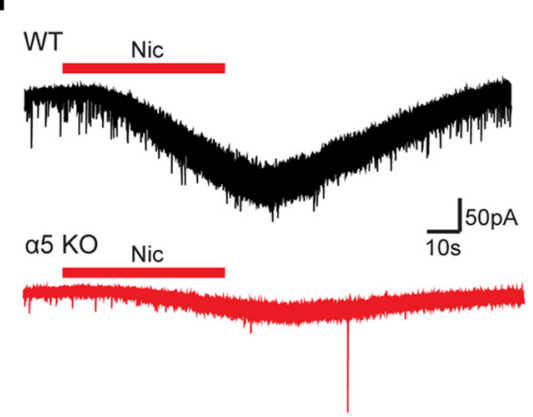

J

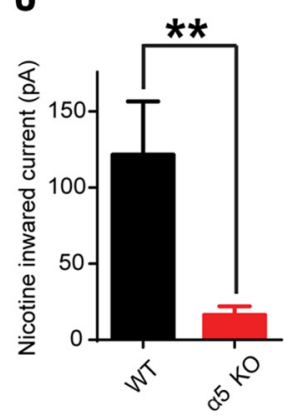

Figure 1. Acetylcholine and nicotine currents in IPR neurons of WT and $\alpha 5 \mathrm{KO}$ mice. $A$, Example traces of ACh (1 mM) current responses in WT and $\alpha 5{ }^{\mathrm{K} 0}$ IPR neurons performed in voltage clamp at a holding potential of $-75 \mathrm{mV}$. B, Mean ACh responses are significantly larger in WT compared with $\alpha{ }^{\mathrm{K} 0}$ neurons (Mann-Whitney $U=70.0, p<0.0001$ ). C, Example responses of IPR neurons from WT and $\alpha 5^{\mathrm{K} 0}$ mice to $100 \mu \mathrm{m}, 300 \mu \mathrm{m}$ and $1 \mathrm{~mm}$ ACh. D, Quantitative comparison of current responses of WT and $\alpha 5^{\mathrm{K} 0}$ neurons show significant differences are maintained across this range of ACh concentrations $\left(F_{1,34}=16.6, p=0.0003\right)$. E, Example traces of current responses to ACh stimulation in IPR neurons from WT and $\alpha 5^{\mathrm{K} 0}$ mice in the presence of the synaptic blockers APV, CNQX, and bicuculline. $F$, Quantification of ACh currents in the presence of synaptic blockers demonstrates that marked differences persist in the direct ACh response in WT compared with $\alpha 5^{\text {KO }}$ neurons (Mann-Whitney $U=4.0, p=0.005$ ). G, Example traces of ACh current responses in WT and $\alpha 5^{\mathrm{K} 0}$ neurons before and after bath application of the $\alpha 4 \beta 2^{*} \mathrm{nAChR}$ antagonist DH $\beta$ E (10 $\mu \mathrm{M}$ ). $\boldsymbol{H}, \mathrm{DH} \beta$ E significantly reduces the mean current amplitude of responses to ACh in both WT and $\alpha 5^{\mathrm{K} 0}$ neurons (Wilcoxon $\left.W=-45.0, p=0.004\right) . I$, Example traces of nicotine $(1 \mu \mathrm{M}$ ) current responses in WT and $\alpha 5^{\mathrm{K} O}$ IPR neurons. J, Mean nicotine responses are significantly larger in WT compared with $\alpha 5^{\mathrm{K} 0}$ neurons (Mann-Whitney $U=31.0, p=0.005$ ). See Figure 1-1, available at https://doi.org/10.1523/JNEUROSCI.0023-18.2018.f1-1 (in table form). ${ }^{*} p<0.05,{ }^{* *} p<0.01,{ }^{* * * *} p<0.0001$.

The Chrna3 and Chrnb4 genes are transcribed on the same DNA strand and, in rodents, they are highly expressed in the MHbV. Chrna5, which is transcribed on the opposite strand, is highly expressed in the IP and moderately expressed in the VTA and is also found in other CNS areas not necessarily correlated with transcription of Chrna3/b4, including layer 6 of the cerebral cortex, CA1 of the hippocampus, and the median/paramedian raphe
(Wada et al., 1990; Marks et al., 1992; Winzer-Serhan and Leslie, 1997; Salas et al., 2003; Hsu et al., 2013). Mouse genomic BACs modified to express GFP or Cre-recombinase have been used to mark and manipulate gene expression in neurons expressing one or more of the genes in the Chrna5/a3/b4 cluster (Frahm et al., 2011; Hsu et al., 2013). Because the three genes at this locus are tightly linked, BAC transgenic models that target one of the three 
A

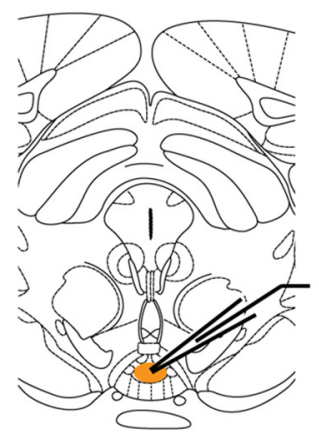

IPR

E

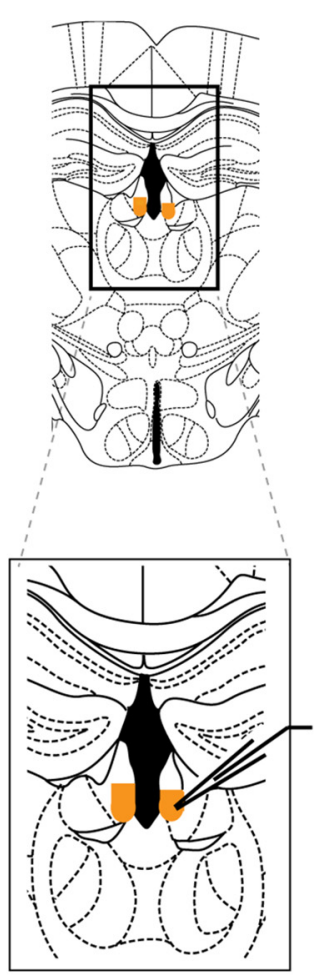

$\mathrm{MHbV}$
B

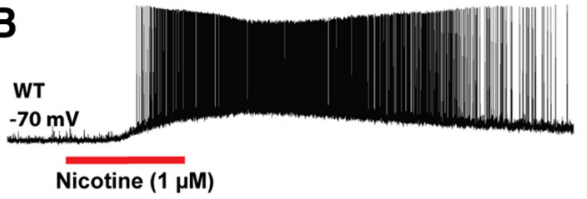

C

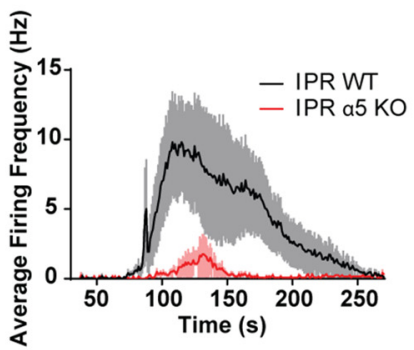

F

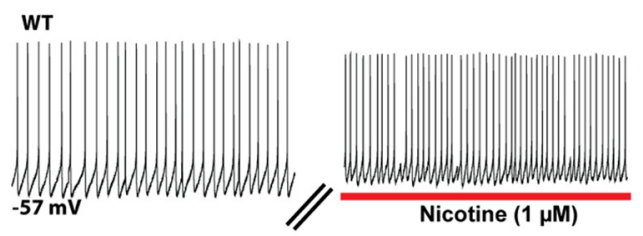

G 좊

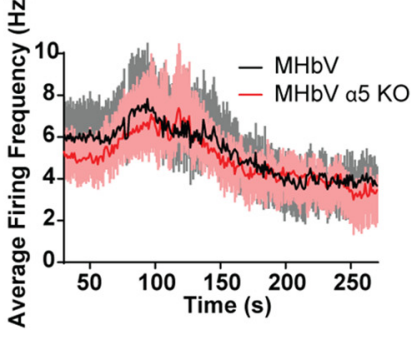

I

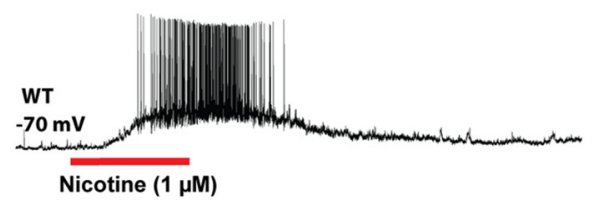

$\mathbf{J}$

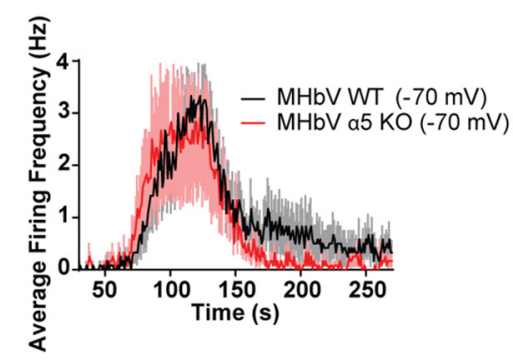

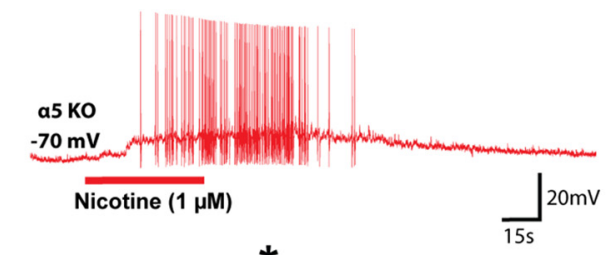

D

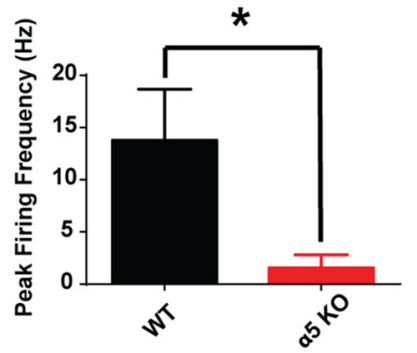

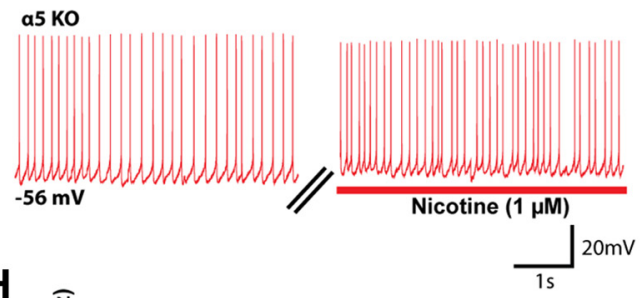
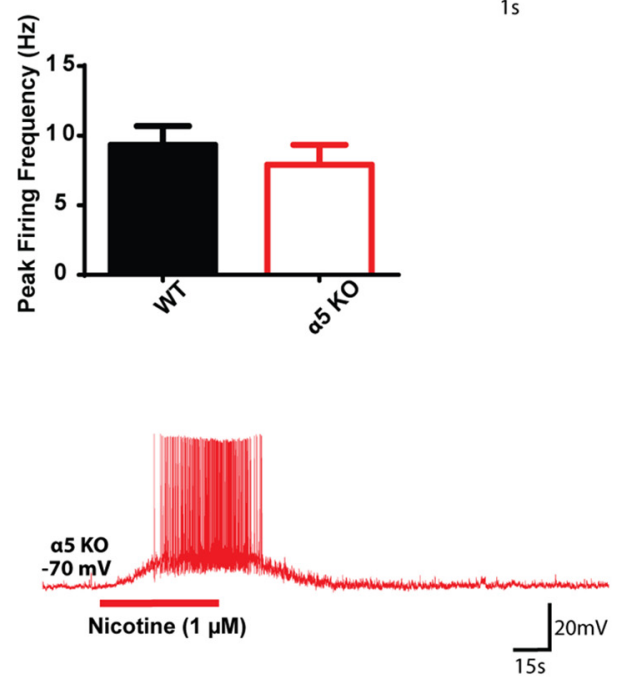

K

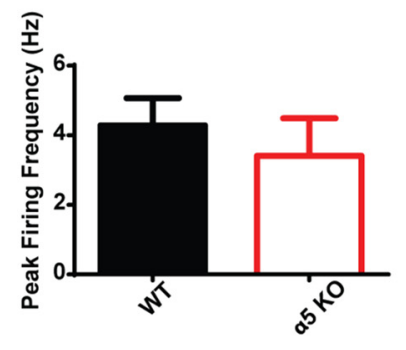

Figure 2. Assessing the effects of nicotine on neuronal excitability in the MHbV and IP in WT and $\alpha 5^{\mathrm{K} 0}$ mice. $A$, Schematic of anterior recording site for IP neurons. $\boldsymbol{B}$, Example traces of IPR neuron responses to nicotine in WT and $\alpha 5^{\mathrm{K} 0}$ mice. C, Average IPR neuronal firing frequency across baseline, nicotine (1 $\left.\mu \mathrm{M}, 1 \mathrm{~min}\right)$, and washout recording. $\boldsymbol{D}$, Peak nicotine-elicited firing frequency is significantly larger for WT than $\alpha 5^{\mathrm{K} 0} \mathrm{IPR}$ neurons (Mann-Whitney $U=46.0, p=0.02$ ). $\boldsymbol{E}$, Schematic illustrating recording sites for MHbV neurons. $\boldsymbol{F}$, Example traces of MHbV neuron responses to nicotine at resting membrane potential in WT and $\alpha 5^{\mathrm{K} 0}$ mice. $\mathbf{G}$, Average MHbV neuronal firing frequency across baseline, nicotine $(1 \mu \mathrm{M}, 1 \mathrm{~min})$ and washout recording. $\boldsymbol{H}$, Peak nicotine-elicited firing frequency does not differ between WT and $\alpha 5^{\mathrm{K} 0}$ mice in MHbV neurons at resting membrane potential (Mann-Whitney $U=49.0, p=0.2$ ). $I$, Example traces of MHbV neuron responses to nicotine in WT and $\alpha 5^{\mathrm{K} 0}$ mice recorded from $-70 \mathrm{mV}$. $\boldsymbol{J}$, Average MHbV neuronal firing frequency across baseline, nicotine $(1 \mu \mathrm{M}, 1 \mathrm{~min})$ and washout recording from $-70 \mathrm{mV}$. $\boldsymbol{K}$, Peak MHbV neuronal firing frequency does not differ between WT and $\alpha 5^{\mathrm{K} 0}$ mice recorded from $-70 \mathrm{mV}$ (Mann-Whitney $U=58.0, p=0.3$ ). See Figure 2-1, available at https://doi.org/10.1523/ JNEUROSCI.0023-18.2018.f2-1 (in table form). ${ }^{*} p<0.05$. 
Table 2. Electrophysiological properties of MHbV neurons in brain slices from ChAT/ ChR2 WT and ChAT/ChR2 $\alpha 5^{\mathrm{K} 0}$ mice

$\begin{array}{lllll}R_{\mathrm{m}}(\mathrm{M} \Omega) & \mathrm{RMP}(\mathrm{mV}) & C_{\mathrm{m}}(\mathrm{pF}) & \text { Spike amplitude }(\mathrm{mV}) & \text { Spike threshold }(\mathrm{mV})\end{array}$

\begin{tabular}{llllll}
\hline WT & $1293 \pm 86$ & $-54 \pm 1$ & $28 \pm 2$ & $45 \pm 2$ & $-37 \pm 1$
\end{tabular}

$\alpha 5^{\mathrm{K} 0} \quad 1182 \pm 112-56 \pm 2 \quad 31 \pm 4 \quad 44 \pm 3 \quad-39 \pm 1$

Intrinsic neuronal properties illustrated are input resistance $\left(R_{\mathrm{m}}\right)$, resting membrane potential (RMP), capacitance $\left(C_{\mathrm{m}}\right)$, spike amplitude, and spike threshold. WT, $n=19$ neurons from 4 mice; $\alpha 5^{\mathrm{K} 0}, n=13$ neurons from 5 mice. Data are shown as mean \pm SEM.

genes at this locus have the disadvantage that they may misexpress the other genes (Ables et al., 2017). To address these limitations and to provide a better model for studies of $\alpha 5$-expressing IP neurons, we constructed a new BAC-derived Chrna $5^{\mathrm{Cre}}$ transgene that completely eliminates the Chrna3 and Chrnb4 transcribed sequences (Fig. 3) and thus cannot overexpress these subunits. The parent BAC clone RP24-318N16 was modified as part of the GENSAT project by the insertion of a Cre recombinase expression cassette immediately after the Chrna5 translation start site, blocking the native Chrna5 open reading frame (Gerfen et al., 2013). This BAC clone contains most of the intergenic region between Chrna5 and the upstream locus Psma4, the entire Chrna5 expressed region, and the entire Chrna3 and Chrnb4 loci, including several regions of high interspecies conservation (Fig. $3 C, D)$. In humans, sequence variants in this genomic region appear to affect CHRNA5 expression levels (Smith et al., 2011). We also examined database information for CTCF binding sites within the locus determined by chromatin immunoprecipitation as part of the ENCODE project (Fig. 3E). Such sites are associated with chromosomal insulators that isolate enhancer function (Ali et al., 2016). We note that a cluster of CTCF-binding sites are found in the short intergenic region between Chrna5 and Chrna3, suggesting that these genes can be independently regulated and the $3^{\prime}$ end of the transgenic construct was chosen to coincide with these sites. We then derived a $\sim 50 \mathrm{~kb}$ subclone of the parent BAC that included all of the available Chrna5 upstream flanking sequence plus the inserted Cre-transcribed region and the Chrna5 exonic, intronic, and 3' untranslated regions, ending between the closely opposed Chrna5 and Chrna3 loci (Fig. 3F, G, and Materials and Methods).

The BAC-derived transgenic construct Chrna5 ${ }^{\mathrm{Cre}}$ was injected into mouse oocytes and three founder lines were derived. Founders were crossed with a Cre-inducible reporter strain, Ai6, which gives ZsGreen expression in the presence of Cre-recombinase (Fig. 4). Overall, the expression pattern of the Cre-induced reporter expression in Chrna $5^{\mathrm{Cre}} / \mathrm{Ai} 6$ mice resembled the previously described expression of a Chrna $5^{\mathrm{GFP}}$ transgene derived from the same parent BAC (Hsu et al., 2013). In the IP, expression driven by all three founder lines closely resembled expression of the endogenous mRNA (Fig. 4A-F), including expression in the IPR, the dorsolateral IP subnucleus (IPDL), and the intermediate and central IP subnuclei (IPI/IPC) and lack of expression in lateral IP subnucleus (IPL). Chrna5-expressing neurons in IPR and IPDL consist predominantly of GABAergic projection neurons (Hsu et al., 2013), whereas IPI contains a preponderance of Chrna5-expressing GABAergic neurons that are local interneurons (Ables et al., 2017). In the VTA, expression of the transgene was very sparse (lines 1 and 2) or absent (line 3; Fig. 4G-I) and clearly did not reproduce the native pattern of Chrna5 mRNA expression in dopaminergic VTA neurons (Fig. 4J). A Chrna5 GFP $\mathrm{BAC}$ transgene derived from the same genomic region is also not expressed in the VTA (Hsu et al., 2013), so it appears that enhancers controlling VTA expression reside outside the region included in the parent BAC.
Two Chrna ${ }^{\text {Cre }}$ transgenic lines showed some expression in the $\mathrm{MHb}$ and $\mathrm{LHb}$, but in different sets of neurons (Fig. $4 K, L$ ). The third transgenic line showed negligible habenula expression (Fig. 4M). In the adult habenula, Chrna5 mRNA is weakly expressed and is not detectable by nonisotopic ISH or FISH (Fig. $4 \mathrm{~N}$ and data not shown), but has been detected by ${ }^{35} \mathrm{~S}-\mathrm{ISH}$ (Franceschini et al., 2002; Salas et al., 2003) and qPCR (Hsu et al., 2013). Because of the weak ISH signal and the lack of available antibodies for immunohistochemistry, the expression of Chrna5 has not been assigned to any specific habenula subnucleus. Marker expression in the two lines that showed habenula signal did not correlate with mRNA expression for the MHbV cholinergic markers vesicular acetylcholine transporter (VAChT) and Chrna3 (Fig. 4O,P). Because of this inconsistency, the habenula expression in these lines can be considered ectopic. Chrna5 ${ }^{\mathrm{Cre}}$ line 3 was used for subsequent functional studies of the IP because of its lack of potentially confounding expression in the habenula and VTA.

Chrna5 mRNA is also expressed in layer 6 of the cerebral cortex and cortical neurons in $\alpha 5^{\mathrm{KO}}$ mice show altered responses to acetylcholine (Bailey et al., 2010). Crosses of the three Chrna ${ }^{\text {Cre }}$ founder mice with the Ai6 reporter line revealed transgene expression in cortical layer 6 in one line (Fig. 5A-C), but with this was associated with significant ectopic expression in a radial pattern consistent with clonal expression (Fig. 5B). To determine the neurotransmitter phenotype of the Chrna ${ }^{\mathrm{Cre}}$ expressing neurons, Chrna ${ }^{\mathrm{Cre}}$-mice were generated expressing a Cre-dependent tdTomato reporter, Ai14 (Madisen et al., 2010), and a Cre-independent marker of GABAergic neurons, Gad67GFP (Tamamaki et al., 2003). This is of interest because $\alpha 5^{\star}$ receptors have been hypothesized to mediate nicotinic responses in VIP-expressing GABAergic interneurons in the mouse prelimbic cortex (Koukouli et al., 2017). Chrna ${ }^{\mathrm{Cre}}$-expression was not detected in GABAergic interneurons (Fig. 5D), implying that it is restricted to glutamatergic pyramidal neurons. This could be because the regulatory sequences contained in the Chrna ${ }^{\mathrm{Cre}}$ transgene do not drive correct expression in GABAergic neurons or because the Chrna5 mRNA is not significantly expressed in these cells. For this reason, we examined the expression of mRNA for Gad1, a GABAergic marker, and Chrna5 in the prelimbic region of WT mice by DFISH (Fig. $5 E$ ). Coexpression of these markers was very rarely observed either within pyramidal cell layers 5 and 6, where most of the Chrna5-expressing neurons reside, or in more superficial layers, where Chrna5 neurons are scattered. However, occasional Gad1-expressing neurons appeared to express low levels of Chrna5 mRNA. This suggests that Chrna5 ${ }^{\mathrm{Cre}}$ driven reporter expression correctly reports that the $\alpha 5$ subunit is expressed in layer 6 cortical pyramidal neurons, but only rarely and/or at very low levels in the interneurons of any layer.

Remarkably, although reporter crosses of Chrna5 ${ }^{\text {Cre }}$ line 3 founder mice showed little cortical expression, these mice bred one generation into a C57BL/6 background (N1) showed extensive, appropriate expression in the cortex (Fig. 5-1, available at https://doi.org/10.1523/JNEUROSCI.0023-18.2018.f5-1). Analysis of the transmission frequency of the Chrna $5^{\text {Cre }}$ allele in line 3 was consistent with Mendelian transmission of a single insertion site ( $\sim 50 \%$ transmission), ruling out the presence of multiple insertion sites driving different expression patterns. We infer that the variable expression in the cortex is due to epigenetic effects on cortical expression of the Cre transgene. No such variability of Cre-dependent transgene expression was observed in the IP, where the induction of ROSA26-targeted ZsGreen (Ai6) and ChR2-YFP (Ai32) transgenes was 100\% penetrant in all genera- 


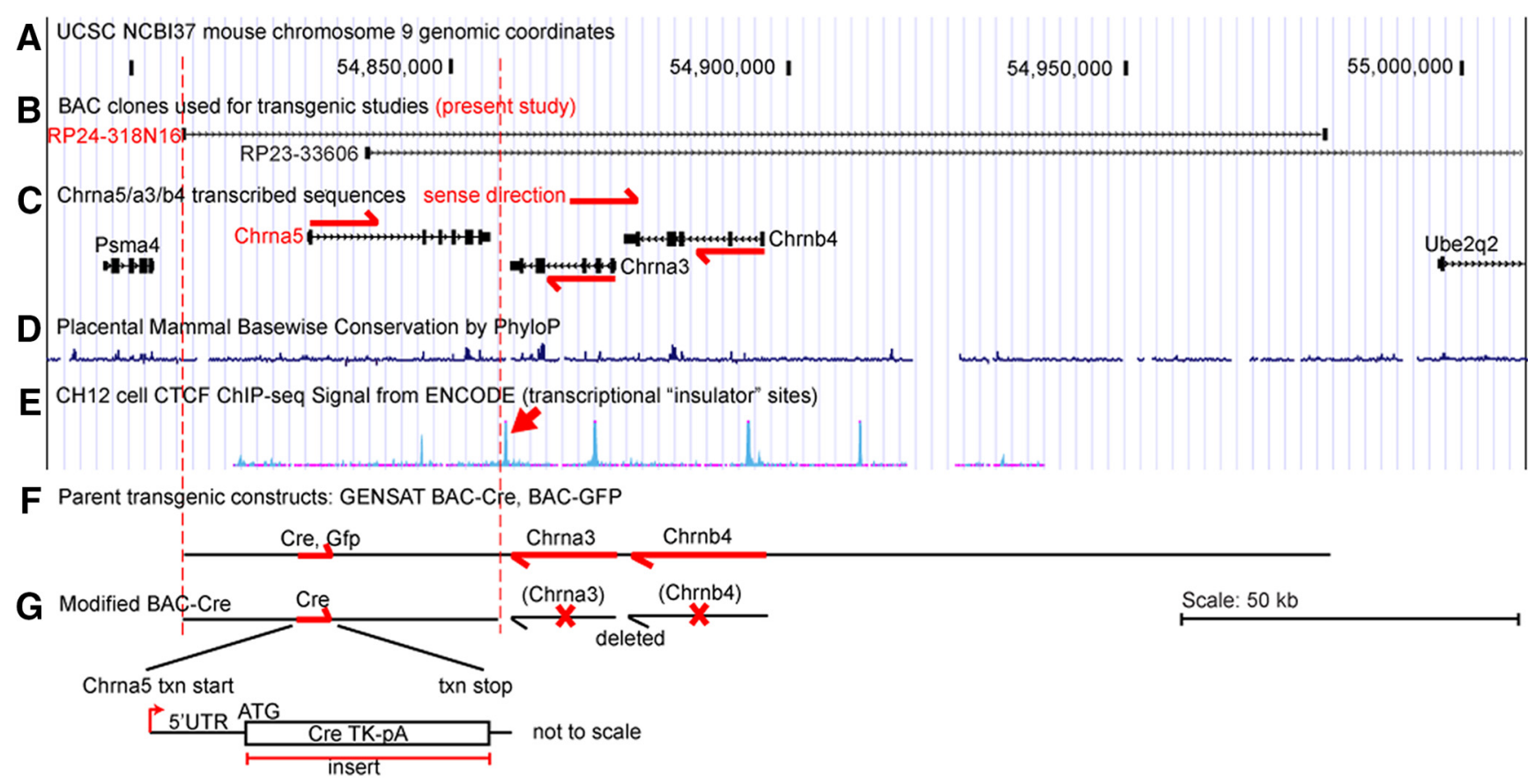

Figure 3. Structure of the mouse Chrna5/a3/b4 gene cluster and Chrna5-derived transgenic models. The upper section ( $\boldsymbol{A}-\boldsymbol{E})$ shows the structure of the Chrna5/a3/b4 genomic locus and BAC clones within the locus that have been used for transgenic studies. The lower section $(\boldsymbol{F}, \boldsymbol{G})$ shows the new transgenic construct reported here. The locus structure and design of transgenic constructs is based on NCBI build 37 of the mouse genome. $\boldsymbol{A}$, Genomic reference coordinates for the Chrna5/a3/b4 locus. B, Location of BACs used, in truncated form, in the present work (RP24-318N16) and in previously reported studies: RP24-318N16 (Hsu et al., 2013), RP23-36606 (Frahm et al., 2011). C, Location of transcribed genes in and flanking the Chrna5/a3/b4 locus. Chrna5 is transcribed on the forward strand and Chrna3 and Chrnb4 are transcribed on the reverse strand as shown. D, Mammalian species conservation within the locus. E, ChIP-seq data for CTCF transcription factor binding sites (TFBS) in mouse CH12 cells (ENCODE project data from UCSC genome browser). These sites tend to occur at "insulator" sites between independently regulated regions of chromatin. Arrow indicates the CTCF-binding peak used to define the distal end of the Chrna5 ${ }^{\text {Cre }}$ transgenic construct. F, Structure of the parent BAC-GFP and BAC-Cre constructs from the GENSAT project. G, Structure of the modified BAC-Cre construct used in the present study. Cre recombinase is inserted at the translation start site (ATG) of the Chrna 5 gene, disrupting expression of the native gene. Dashed red lines indicate the extent of the transgenic construct in the context of the genomic locus. The transcription start site is indicated by an arrow. The Chrna3 and Chrnb4 transcription units are entirely deleted from the transgenic construct.

tions. The Chrna $5^{\text {Cre }}$ transgenic lines derived here contain only the Chrna5 gene and upstream regulatory sequences and do not contain coding or regulatory information from the Chrna3/b4 region of the combined Chrna5/a3/b4 locus. Therefore, these results demonstrate the autonomous transcriptional regulation of the Chrna5 gene in specific brain regions (IP, cortex) independent of enhancers that might reside in the Chrna3/b4 region of the gene locus. In other cell types, such as the VTA, information from outside the transgenic construct used here appears to be required for correct expression. These findings may help to provide a framework for the interpretation of the noncoding polymorphisms found in smoking-related haplotypes (Barrie et al., 2017).

\section{Specific projections of Chrna5-expressing neurons in the IP and the mesopontine raphe}

The IP subnuclei have distinct afferents and efferents. Chrna5 ${ }^{\mathrm{Cre}}$ is expressed in IPR and IPC/IPI, which receive input from $\mathrm{MHbV}$, and excluded from IPL, which receives input from the dorsal MHb (Quina et al., 2017). To map the specific efferents of the Chrna5 ${ }^{\text {Cre }}$ neurons, we used a Cre-dependent AAV tracttracing strategy. Two viruses were coinjected, one expressing synaptophysin-EGFP (sypGFP), which prominently labels the presynaptic area of efferent fibers, and one expressing tdTomato, which labels cell bodies and fibers but is not specifically transported to synaptic areas. In each injected area, the majority of labeled neurons coexpressed both markers. In case IP-a1, AAV was injected into the IPR of a Chrna5 ${ }^{\mathrm{Cre}}$ mouse (Fig. $6 A, B$ ), with a small number of labeled neurons also noted in the adjacent median/paramedian raphe (MnR/PMnR; Fig. 6C,D). Prior work has suggested that SST-expressing GABAergic neurons in IPR make presynaptic connections onto afferents from the MHbV, which may modulate habenula input (Zhao-Shea et al., 2013). These SST neurons in IPR have been shown to be a subpopulation of the Chrna5-expressing neurons (Hsu et al., 2013). However, a synaptic connection by these neurons within the IP has not been directly demonstrated. In case IP-a1, labeled cell bodies in the IP were restricted to IPR, but labeled synaptic puncta were observed in IPC and in symmetrical bands running between IPI and IPL (Fig. 6A). The synaptic labeling was sometimes associated with ChAT labeling in MHbV afferents (Fig. $6 E-G$ ), although it is not possible to determine with certainty whether these synapses are associated with these afferents or with local IP neurons. Paradoxically, no tdTomato-labeled fibers of passage were observed between IPR and the ventral synaptic puncta, suggesting that these synapses may be derived from the small population of labeled PMnR neurons. To test this hypothesis, in case MnR-a1, we injected sypGFP + tdTomato expressing viruses into the PMnR of a Chrna5 ${ }^{\text {Cre }}$ mouse caudal to the IP (Fig. $6 H$ ). Although fewer neurons were labeled compared with case IP-a1, dense synaptic labeling was observed in the ventral IP (Fig. 6I-K). To further characterize the raphe-IP projection, in case MnR-a2, we injected a GFP tract-tracing virus into the PMnR of an SST ${ }^{\text {Cre }}$ mouse (Fig. $6 L$ ). This also produced strongly labeled afferents to IPC and the border between IPI and IPL (Fig. 6M). DFISH for Chrna5 and SST mRNA showed that the SST-expressing neurons in IPR are a subset of the Chrna5-expressing neurons found there (Fig. $6 \mathrm{~N}$ ). However, in the MnR/PMnR, expression of these tran- 

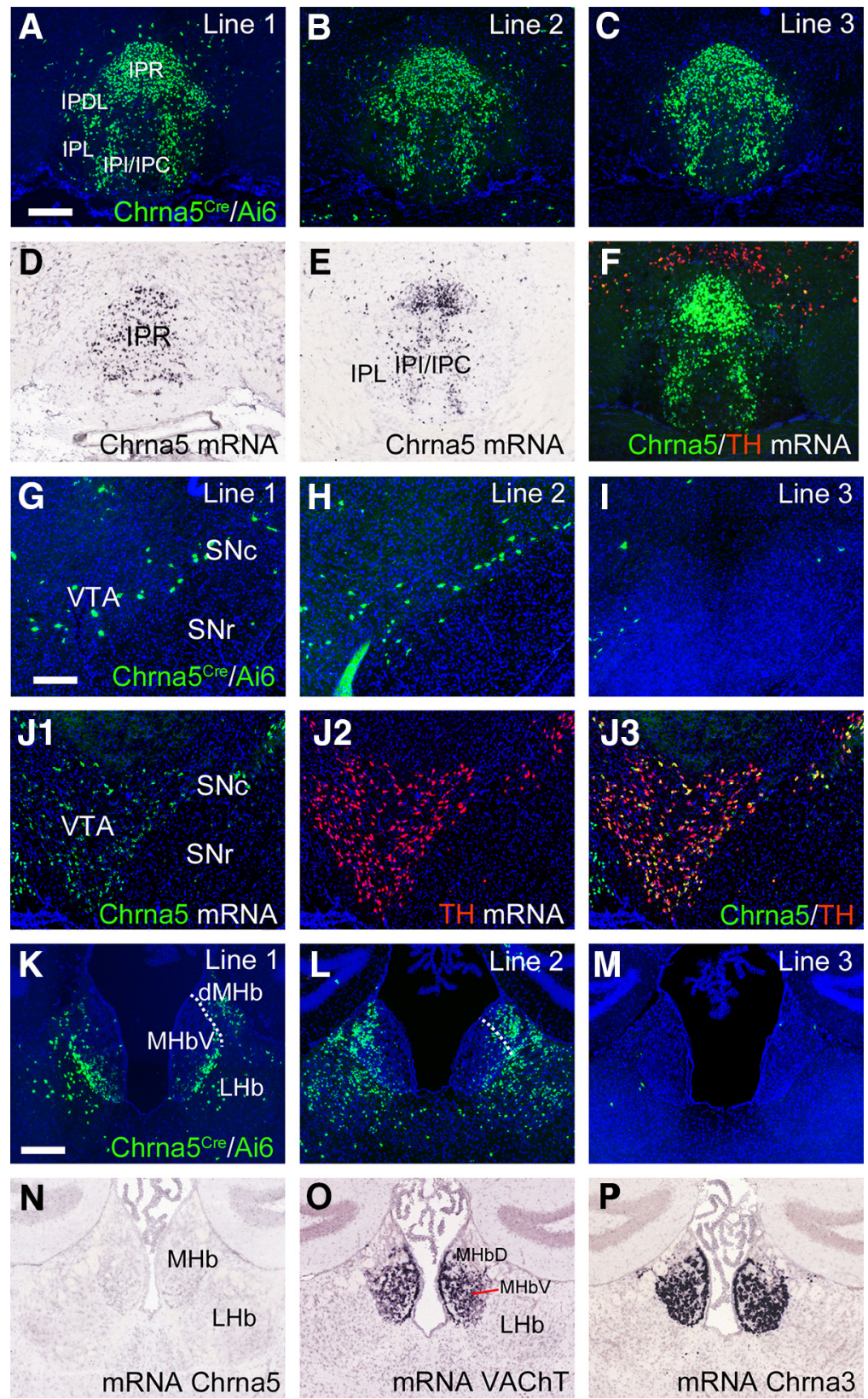

Figure 4. Chrna5 ${ }^{\mathrm{Cre}}$-mediated reporter expression in subcortical areas. Chrna $5^{\mathrm{Cre}}$ mice from three founder lines were interbred with the Ai6 reporter strain, conditionally expressing the marker ZsGreen to characterize cell-specific cre-mediated expression. A-C, ZsGreen fluorescence in the interpeduncular nucleus corresponding to axial level bregma -3.5 in a standard atlas (Paxinos and Franklin, 2001). Expression is nearly identical when driven by each of three (re-driver lines. D, E, Chrna5 ISH at levels slightly rostral $(\boldsymbol{D})$ and slightly caudal $(\boldsymbol{E})$ to that shown in $\boldsymbol{A}-\boldsymbol{C}$. $\boldsymbol{F}$, Chrna5/TH DFISH at a level close to that shown in $\boldsymbol{A}-\boldsymbol{C}$. G-I, ZsGreen fluorescence is sparse (lines 1 and 2) to absent (line 3) in the VTA (bregma - 3.0). J, FISH data for Chrna5 and TH mRNA in the VTA at a level similar to $\mathbf{G}-\mathbf{I}$ demonstrating that the expression of the endogenous Chrna5 mRNA is more extensive than that of the Chrna5 ${ }^{\text {Cre }}$-driven reporter. $\boldsymbol{K}-\boldsymbol{M}$, ZsGreen fluorescence in the habenula. $\boldsymbol{N}-\boldsymbol{P}$, Comparison of expression for Chrna5 (undetectable), VAChT, and Chrna3 mRNA in the habenula aligned approximately with the level shown in $\boldsymbol{K}-\boldsymbol{M}$. Data in $\boldsymbol{D}, \boldsymbol{E}, \boldsymbol{N}, \mathbf{0}, \boldsymbol{P}$ are from the Allen Brain Atlas; data in $\boldsymbol{F}$ and $\boldsymbol{J}$ are from the Allen Transgenic Characterization Project (courtesy of Dr. HongkuiZeng). All dark-field sections shown are counterstained with DAPI (blue). LHb, Lateral habenula; MHb, medial habenula (MHbD, dorsal, and MHbV , ventral subnuclei); SNc, substantia nigra, pars compacta; SNr, substantia nigra, pars reticulata. Scale bar, $200 \mu \mathrm{m}$.

scripts does not overlap (Fig. 6O). We conclude that IPR neurons do not project within the IP as previously hypothesized, but rather, the IP receives input from distinct populations of Chrna5- and SST-expressing neurons in the raphe.

Prior work has shown that IP efferents project predominantly to the raphe and mesopontine tegmentum, with distinct projections for the IP subnuclei (Quina et al., 2017). Viral tract tracing of the efferents of Chrna ${ }^{\text {Cre }}$-expressing neurons in IPR shows synaptic labeling in a subset of these areas (Fig. $7 A-I$ ). In the median raphe, synaptic puncta from IPR projections generally appear in $\mathrm{PMnR}$, surrounding but usually not overlapping 5HT neurons in MnR proper (Fig. $7 A, B$ ). Labeling in the rostral part of dorsal raphe was sparse (DR; Fig. 7C,D). Intense synaptic labeling was observed in the rhabdoid nucleus (Rbd; Fig. 7C,E), which can be identified by immunofluorescence for the orphan receptor Gpr151. The expression of this orphan receptor in Rbd can probably be attributed to inputs from Gpr151-expressing excitatory neurons in the LHb (Broms et al., 2015), showing an interesting confluence of inhibitory IP and excitatory $\mathrm{LHb}$ inputs to this nucleus. Projections from Chrna5 ${ }^{\text {Cre }}$ IP neurons are sparse in the laterodorsal tegmental nucleus (LDTg) and are not closely associated with the cholinergic neurons there (Fig. $7 F, G$ ). Projections are absent from the central dorsal tegmental nucleus (DTg; Fig. $7 \mathrm{H}, I$ ), although there is strong synaptic labeling in the surrounding the central pontine gray (CGPn) and near the midline, in the nucleus incertus (NI; Fig. $7 I)$. Viral tract tracing of Chrna ${ }^{\mathrm{Cre}}$ neurons in MnR (case MnR-a1; Fig. 7J-L) shows that these neurons also form synaptic connections to the mesopontine raphe and dorsal tegmentum in a pattern that overlaps that of the IPR efferents but spares Rbd. The caudal projections of Chrna5 ${ }^{\text {Cre }}$ IP neurons in IPR appear similar to IP projections described in the rat (Lima et al., 2017).

\section{Activation of IP Chrna5 neurons is aversive}

To test the behavioral function of the IP Chrna5 neurons, we generated an optogenetic model using Cre-inducible expression of ChR2. Chrna5 ${ }^{\mathrm{Cre}}$ mice were interbred with mice homozygous for a floxed-stop ChR2-EYFP cassette targeted to the Gt(ROSA)26Sor gene locus (Madisen et al., 2012). ChR2 expression was observed in the IP, but not in adjacent structures such as the VTA, which might confound behavioral experiments (Fig. $8 A)$. IP ${ }^{\text {ChR2 }}$ neurons and fibers were found in IPR, IPC, and IPI, areas that receive glutamatergic/cholinergic afferents from the MHbV (ChAT label; Fig. 8B), but not in IPL, which receives glutamatergic/peptidergic inputs from the MHbD (SP label; Fig. $8 C$ ). Therefore, IP ${ }^{\mathrm{ChR} 2}$ mice allow specific functional testing of the MHbV-IP pathway most often implicated in the effects of nicotine.

To assess the light responsiveness of IP ${ }^{\mathrm{ChR} 2}$ neurons, we recorded cellular responses in IPR neurons in acute brain slice 

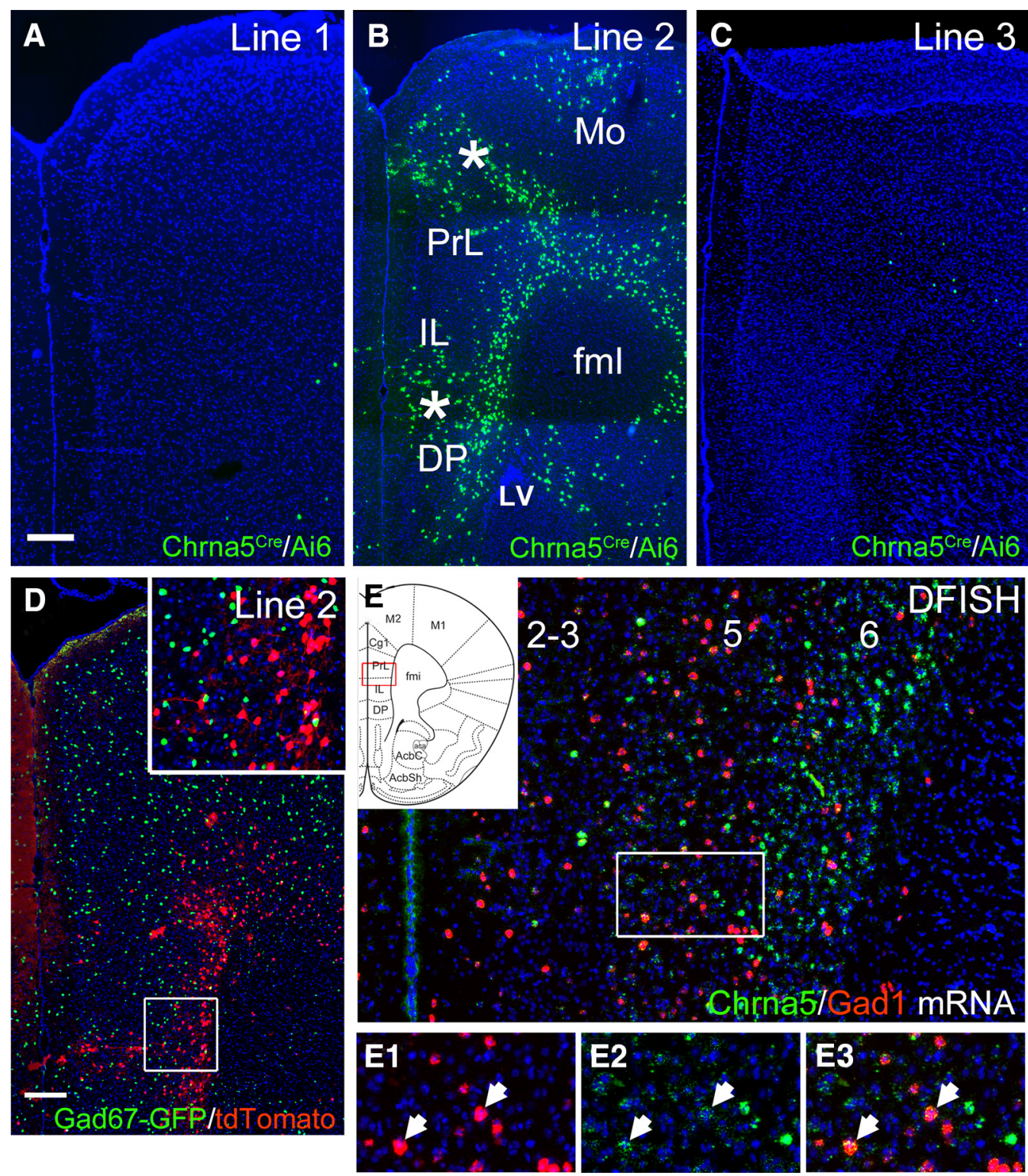

Figure 5. Chrna $5^{\text {Cre }}$-mediated reporter expression in the cerebral cortex. A-C, Expression of ZsGreen in the cerebral cortex of Chrna $^{{ }^{(\mathrm{Cre}}}$ mice from three founder lines interbred with the Ai6 reporter strain. Lines 1 and 3 exhibit low expression; line 2 exhibits appropriate expression in deep cortical layers, but expression is also seen sporadically in more superficial cells that appear to be clonal in origin and are likely to result from occasional developmental activation of the reporter (asterisks). Coronal sections at bregma 1.9. D, Colabeling of GABAergic interneurons in green (Gad67-GFP) and Chrna5 ${ }^{\mathrm{Cre}}$ neurons in red (Chrna5 ${ }^{\mathrm{Cre}}$ and Ai14/tdTomato). Inset detail shows that Chrna5 ${ }^{\text {Cre }}$ neurons are exclusively excitatory pyramidal cells. Also shown is a coronal section at bregma 2.3. E, DFISH for Chrna5 and Gad1/Gad67 mRNA. Little overlap in expression is observed, but occasional Gad1-expressing cells appear to express low levels of Chrna5 (inset, arrows). Fml, Forceps minor, corpus callosum; DP, dorsal peduncular cortex; IL, infralimbic cortex; Iv, lateral ventricle; Mo, motor cortex; PrL, prelimbic cortex. Scale bar, 200 $\mu \mathrm{m}$. See Figure 5-1, available at https://doi.org/10.1523/JNEUROSCI.0023-18.2018.f5-1.

preparations (see Materials and Methods) using whole-cell current-clamp $(n=3)$ and cell-attached $(n=5)$ recordings. Of eight recorded cells, only two were spontaneously firing at $<1$ $\mathrm{Hz}$; the others were silent in the absence of light stimulus. Light responsiveness was tested using $2 \mathrm{~s}$ trains of $10 \mathrm{~ms}$ light pulses at stimulus frequencies of 5, 10, 20, and $50 \mathrm{~Hz}$. Eight of 8 neurons tested were able to fire action potentials at $1: 1$ correspondence with the $5 \mathrm{~Hz}$ and $10 \mathrm{~Hz}$ stimuli and $6 / 8$ neurons were able to follow a $20 \mathrm{~Hz}$ stimulus (Fig. 8C1-C3). However, in the presence of a $50 \mathrm{~Hz}$ stimulus, some neurons produced an action potential in response to the first light pulse and then entered a depolarization block (5/8 cells; Fig. 8C4), whereas others briefly fired action potentials at a 1:1 correspondence, but were unable to do so for 2 s (2/8 cells; Fig. 8D). Therefore, for all behavioral experiments, a $20 \mathrm{~Hz}$ stimulus frequency was used except when assessing somatic nicotine withdrawal signs, for which a specific published stimulus protocol was followed (see Materials and Methods).

To assess the effect of IP stimulation on behavior, IP ${ }^{\mathrm{ChR} 2}$ mice and controls were implanted with fiber-optic cannulas just dorsal to or slightly within IPR (see Materials and Methods; Fig. 9A, Fig. 9-1, available at https://doi.org/10.1523/JNEUROSCI.002318.2018.f9-1). Light stimulation from cannulas in this dorsal position resulted in the induction of cFos expression in neurons throughout the IP (Fig. 9-2, available at https://doi.org/10.1523/ JNEUROSCI.0023-18.2018.f9-2). Because visible light and drug administration can in themselves affect behavior, all behavioral experiments were structured as a comparison between genotypes, in which IP ${ }^{\mathrm{ChR} 2}$ mice and controls received identical light stim- 

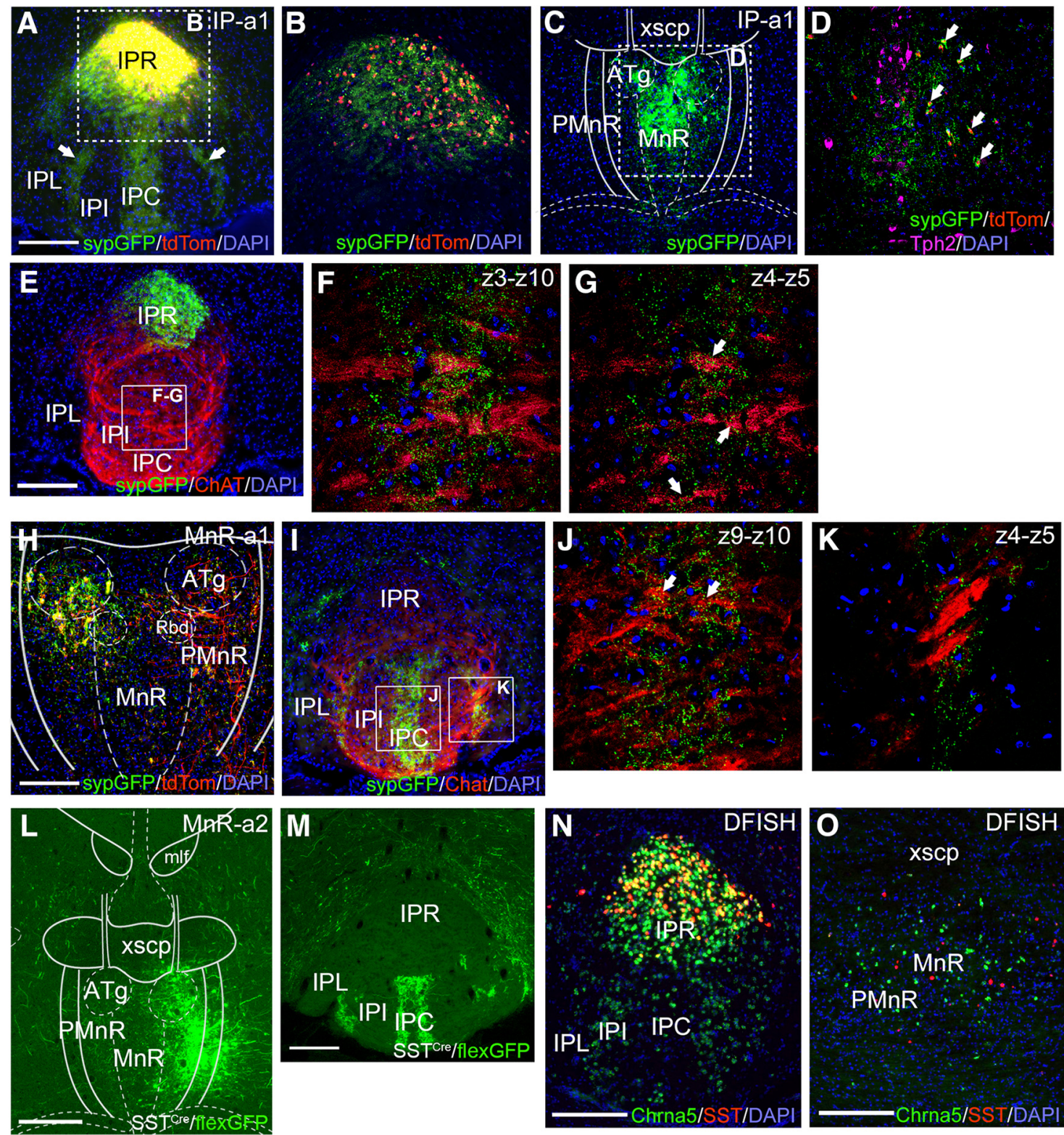

Figure 6. Anterograde tracing of local projections of Chrna5 ${ }^{\text {Cre }}$ neurons in the IP and Chrna $5^{\text {Cre }}$ and SST ${ }^{\text {Cre }}$ neurons in the median raphe. $\boldsymbol{A}-\boldsymbol{K}$, Mixture of (re-dependent (flex) AAVs encoding a red marker in cell bodies and axons (tdTomato) and a green marker targeted to presynaptic areas (sypGFP) was injected into the IPR (Case IP-a1; $\boldsymbol{A}-\boldsymbol{G}$ ) and MnR/PMnR (Case MnR-a1; $\boldsymbol{H}-\boldsymbol{K}$ ) of Chrna ${ }^{\text {Cre }}$ mice. $A$, Injected area in the IPR (bregma 3.5). The sypGFP signal is overexposed to show faint synaptic labeling in the IPC and at the border between IPI and IPL. $B$, Confocal image of the injected area showing cellular colocalization of tdTomato and sypGFP. No synaptic labeling or projecting fibers are observed in the IPR beyond the injected area. $C, D, A$ more caudal section (bregma -4.2) shows that virally labeled cell bodies are also found among Chrna5 ${ }^{\text {Cre }}$-expressing neurons in the PMnR caudal to the IP. 5HT neurons in the MnR are identified by immunostaining for Tph2. Overlay in C is from a standard atlas at bregma - 4.24 (Paxinos and Franklin, 2001). $\boldsymbol{E}$, Section adjacent to that shown in $\boldsymbol{A}$ immunostained for ChAT to show afferent fibers from the MHbV.F, G, Thick and thin confocal Z-stacks of sypGFP-labeled synapses in IPC. Arrows indicate synaptic labeling adjacent to cholinergic MHbV fibers. $\boldsymbol{H}$, Case MnR-a1. Flex-sypGFP and flex-tdTomato viruses were injected in the PMnR of a Chrna5 ${ }^{\text {Cre }}$ mouse. Overlay is at bregma -4.36 . I, Labeled Chrna ${ }^{\text {Cre }}$ PMnR neurons project to IPC, and the border between IPI and IPL. No labeled cell bodies are observed in IPR, confirming that the injection is localized to PMnR. J, Thin Z-stack confocal image of sypGFP-labeled synapses in IPC. Arrows indicate synaptic labeling adjacent to cholinergic MHbV fibers. $K$, Confocal image of sypGFP-labeled synapses at the border between IPI and IPL, which do not appear to overlap MHbV fibers. $L, M$, Case MnR-a2, viral tract-tracing of SST ${ }^{\text {Cre }}$-expressing neurons in the PMnR. L, Site of injection of a Cre-dependent AAV encoding GFP in cell bodies and axons in the PMnR. Overlay is at bregma $-4.24 . M$, Labeled fibers in the IPC and the border between IPI and IPL. No labeled cell bodies are observed in the IP, confirming that the injection is localized to PMnR. $\boldsymbol{N}, \mathbf{O}$, DFISH for Chrna5 and SST mRNA. Chrna5 and SST are coexpressed in IPR (bregma - 3.7; $\boldsymbol{N}$ ), but identify distinct, intermingled neurons in the PMnR (bregma - 4.3;0). ATg, Anterior tegmental nucleus; MnR, median raphe nucleus; PMnR, paramedian raphe nucleus; Rbd, rhabdoid nucleus; mlf, medial longitudinal fasciculus; xscp, decussation of the superior cerebellar peduncle. Scale bars: $A, E, H, M-0,200 \mu \mathrm{m} ; L, 400 \mu \mathrm{m}$.

ulation and/or pharmacological treatment. To assess for any effect of IP activity on acute locomotion, $\mathrm{IP}^{\mathrm{ChR} 2}$ mice were tested in an open-field arena (Fig. $9 B-E$ ). During the stimulus phase of the trial, a small-magnitude increase in distance traveled during the light on intervals was noted, but there was no effect of genotype [repeated-measures $(\mathrm{RM})$-ANOVA, genotype $\times$ light, effect of genotype: $F_{(1,18)}=0.24, p=0.63$, effect of light: $F_{(1,18)}=13.89$, $p=0.0015$; Fig. $9 B, C]$, nor were significant differences noted between genotypes in the three phases of the experiment (multiple-hypothesis-corrected $t$ test; baseline $t_{(54)}=1.10, p=$ 0.83 , stimulation $t_{(54)}=0.49, p>0.99$, poststimulation $t_{(54)}=$ $0.24, p>0.99$; Fig. $9 D$ ). In the open-field test, avoidance of the center of the enclosure has been used as a model of anxiety (Bailey and Crawley, 2009). A small-magnitude decrease in center 

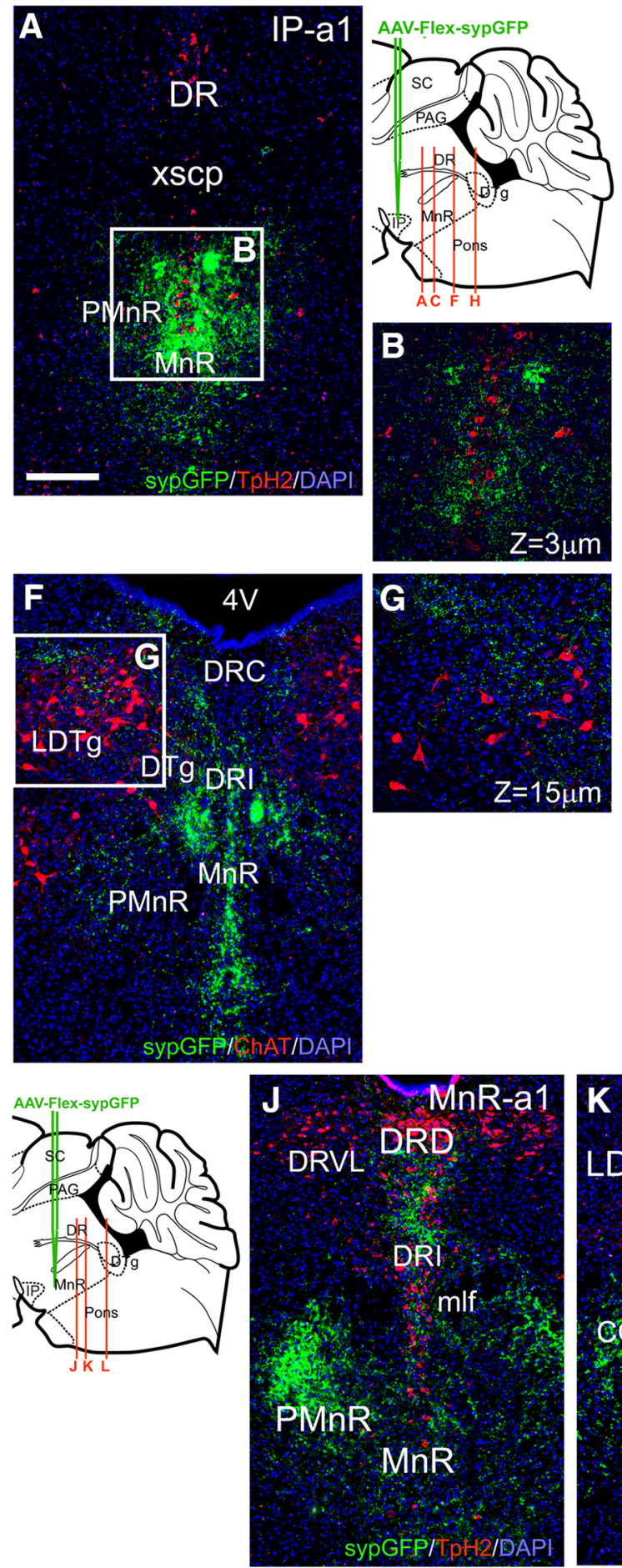
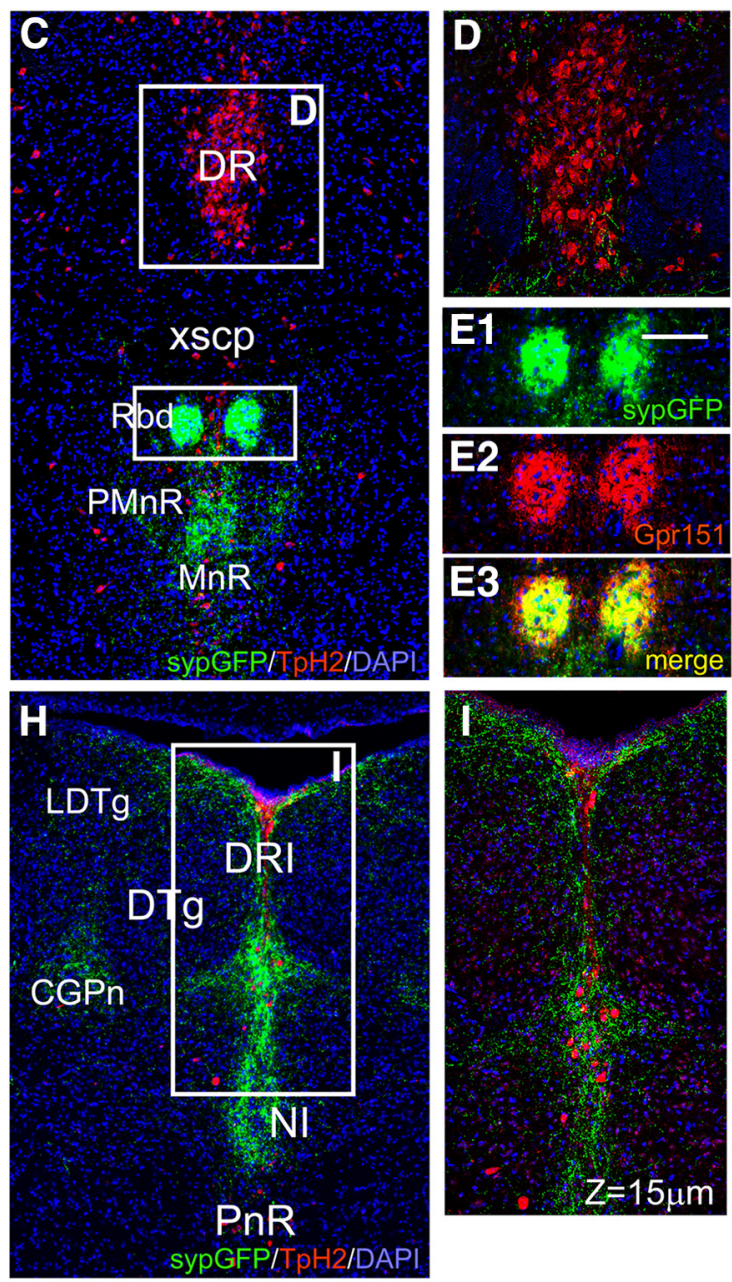

$Z=15 u m$
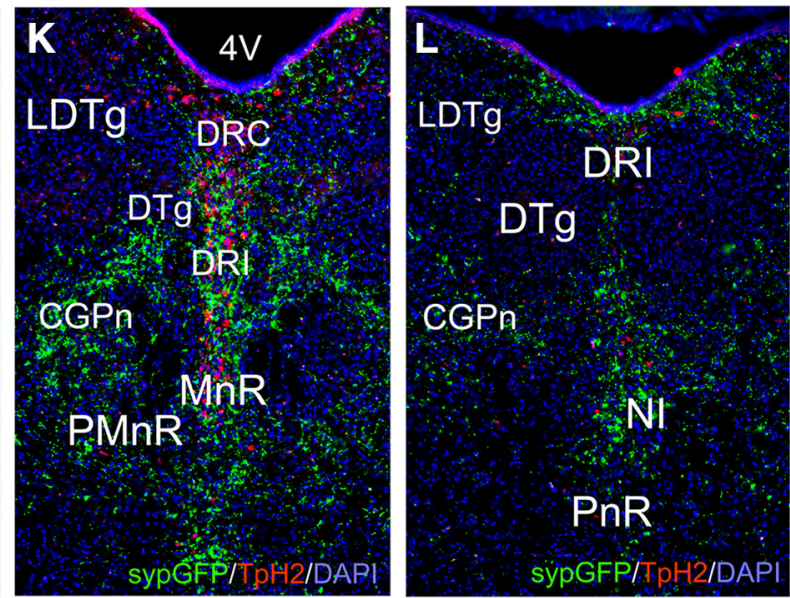

Figure 7. Efferents of Chrna5-expressing neurons to the pontine raphe and tegmentum. $A-I$, Caudal projections of IPR neurons labeled with Cre-dependent AAVs encoding a red marker in cell bodies and axons (tdTomato) and a green marker targeted to presynaptic areas (sypGFP), as shown in Figure 5A. A, B, Synaptic labeling in the MnR/PMnR (bregma 4.2). Serotonergic neurons are marked by immunofluorescent staining for Tph2. Confocal image in $\boldsymbol{B}$ shows that labeling surrounds but usually does not overlap Tph2-expressing cell bodies. $\boldsymbol{C}, \boldsymbol{D}$, Synaptic labeling in the rhabdoid nucleus and MnR/PMnR (bregma 4.5). Confocal view shows that fibers are very sparse in the DR. 5 HT neurons are identified by immunostaining for Tph2.E, Coimmunostaining for Gpr151 and sypGFP in the rhabdoid nucleus. $F, G$, Synaptic labeling in the caudal MnR/PMnR, DR, and dorsal tegmentum (bregma 5.0). Cholinergic neurons are marked by immunofluorescent staining for ChAT. Sparse sypGFP labeling is noted in the LDTg, which does not overlap the ChAT-expressing neurons. $\mathbf{H}, \mathbf{I}$, Synaptic labeling in the pontine tegmentum (bregma 5.3). Synaptic labeling is prominent in DRI and $\mathrm{NI}$, but absent from DTg and PnR. J-L, Caudal projections of Chrna5 ${ }^{\text {Cre }}$-expressing MnR neurons in case MnR-a1, labeled as shown in Figure $5 H$. J, Prominent synaptic labeling in DRI and in PMnR ipsilateral to the injection (bregma 4.8). $\boldsymbol{K}$, Labeling in (GPn and DRI sparing DTg/LDTg (bregma 5.0, comparable to $\boldsymbol{F}$ ). $\boldsymbol{L}$, Projections to the caudal part of the pontine tegmentum, including NI (bregma 5.3, comparable to $\boldsymbol{H}$ ). MnR, Median raphe nucleus; PMnR, paramedian raphe nucleus; Rbd, rhabdoid nucleus; mlf, medial longitudinal fasciculus; xscp, decussation of the superior cerebellar peduncle; DTg, dorsal tegmental nucleus; LDTg, laterodorsal tegmental nucleus; PnR, pontine raphe nucleus; NI, nucleus incertus; CGPn, central gray of the pons; DR, dorsal raphe nucleus; DRI, dorsal raphe nucleus, interfascicular part; DRD, dorsal raphe nucleus, dorsal part; DRVL, dorsal raphe nucleus, ventrolateral part; DRC, dorsal raphe nucleus, caudal part. Scale bar, $200 \mu \mathrm{m}$. 

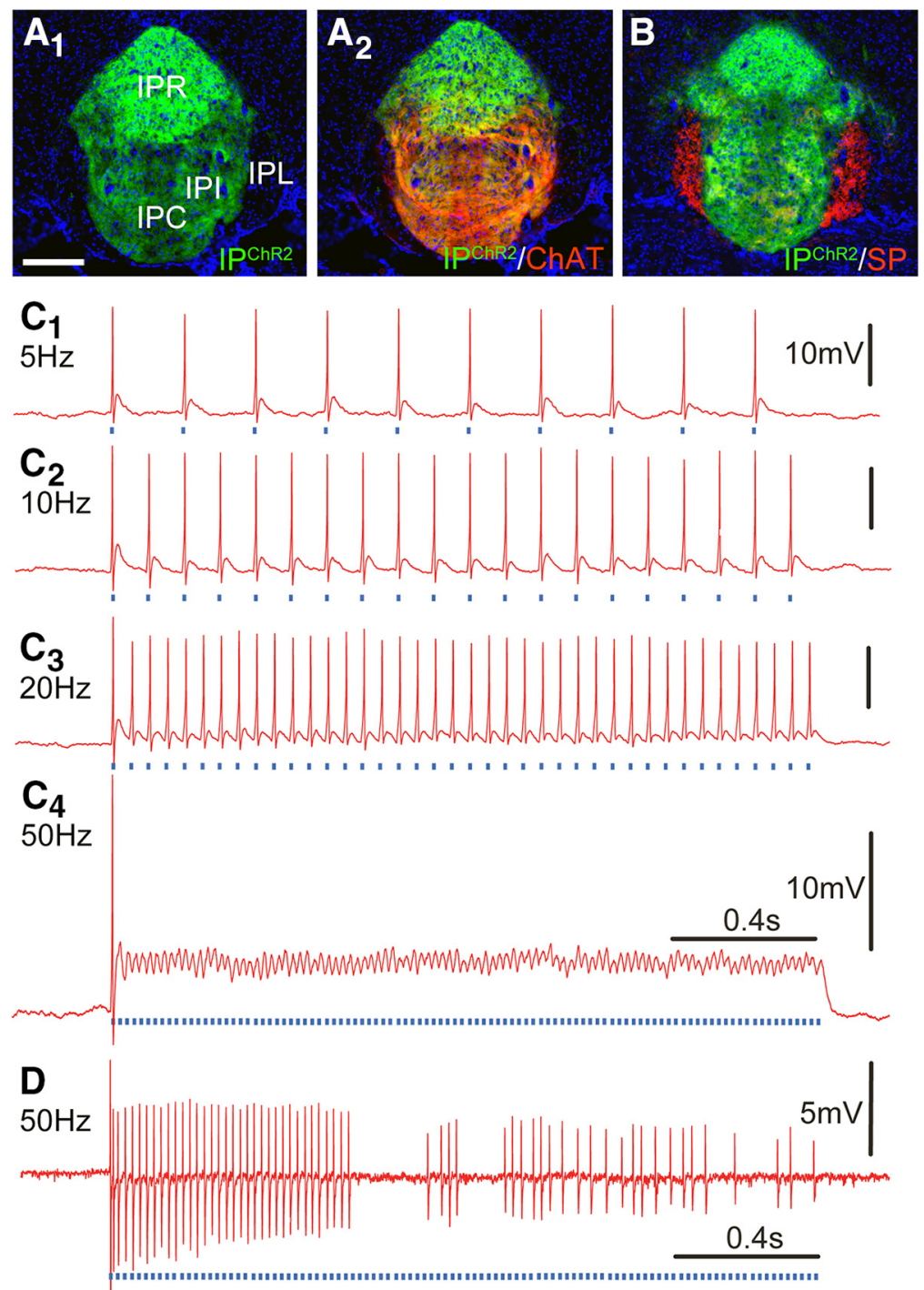

Figure 8. Optogenetic activation of Chrna ${ }^{\text {Cre }}$ neurons using transgenic expression of ChR2. A, Expression of ChR2-EYFP in a Chrna $5^{\mathrm{Cre}} / \mathrm{Ai} 32$ mouse $(\boldsymbol{A} \boldsymbol{1})$ and the same section also showing immunofluorescence for ChAT expressed in afferents from the MHbV (A2). B, An adjacent section stained for SP expressed in MHbD afferents to the IPL, which does not contain Chrna5 $5_{\text {Cre }}$ expressing neurons. $C$, Current-clamp recording of the optogenetic stimulation of a typical $\mathrm{Ch}$ rna $5^{\mathrm{Cre}}$-expressing neuron in IPR. The cell may be entrained to fire action potentials in response to light pulses ( $473 \mathrm{~nm}, 10 \mathrm{~ms}$ ) delivered at $5 \mathrm{~Hz}, 10 \mathrm{~Hz}$, and $20 \mathrm{~Hz}$ (C1-C3), but when stimulated at $50 \mathrm{~Hz}$ (C4) fires a single action potential, followed by excitatory block characterized by continuous depolarization and superimposed oscillations from ChR2 currents. $\boldsymbol{D}$, Cell-attached recording of a less-frequently observed response by a different $\mathrm{Chrna} 5{ }^{\mathrm{Cre}}$-expressing IPR neuron, which could be initially entrained to light pulses delivered at $50 \mathrm{~Hz}$, but after $\sim 1$ s responded sporadically.

occupancy was observed during the lights-on intervals, but there was no effect of genotype (RM-ANOVA: genotype $\times$ light, effect of genotype: $F_{(1,18)}=1.26, p=0.28$, effect of light: $F_{(1,18)}=9.468$, $p=0.0065$; Fig. $9 E)$. Similarly, no difference between genotypes was detected in another assay of anxiety, the light/dark box (unpaired $t$ test between genotypes: $t_{(28)}=0.97, p=0.34$; Fig. $9 F$ ).

Prior work has reported that optogenetic stimulation of GABAergic neurons in the IP can elicit somatic signs associated with nicotine withdrawal, which include scratching, shaking, nodding, backing, rearing, and chewing (Zhao-Shea et al., 2013). To exactly match the stimulation protocol used in the prior work, we used intermittent optogenetic stimulation at $50 \mathrm{~Hz}$ in a standard housing cage (see Materials and Methods). $\mathrm{IP}^{\mathrm{ChR} 2}$ mice showed no difference from controls in any of the somatic signs tested ( $t$ test between genotypes for each behavior, $p>0.99$ for all seven behaviors; Fig. $9 G$ ). In the prior study of somatic signs, the IP of Gad2 ${ }^{\text {Cre }}$ mice was injected with a conditional AAV vector expressing $\mathrm{ChR} 2$ in all GABAergic neurons in the injected area. The amount of injected virus $(1 \mu \mathrm{l})$ was approximately twice the entire volume of the IP and is likely to have diffused into the surrounding tegmental nuclei, all of which contain GABAergic neurons, although the extent of viral spread was not discussed. Therefore, the prior result may represent offtarget effects.

To determine whether the stimulation of $\alpha 5$-expressing IP neurons is reinforcing, aversive, or neutral, we used RTPP in a two-compartment shuttle box. To control for effects of preexisting preference or habituation, RTPP was performed with a $2 \mathrm{~d}$ reversal structure. On day 1 , mice were assigned randomly to receive the light stimulation on the right or left side of the box, referred to here as the "A" side. On the subsequent day of testing, light stimulation was delivered on the opposite " $\mathrm{B}$ " side. No significant preference or avoidance was observed on day 1 of a $2 \mathrm{~d}$ RTPP experiment; however, on day 2 , a significant avoidance of the stimulated side was observed in IP ${ }^{\text {ChR2 }}$ mice (RM-ANOVA: genotype $\times$ day, effect of genotype: $F_{(1,18)}=14.71, p=0.0012$, effect of day: $F_{(1,18)}=0.83, p=0.38$; Fig. $\left.10 A\right)$. Division of the test period into $5 \mathrm{~min}$ intervals for IP ${ }^{\mathrm{ChR} 2}$ mice on the two test days revealed an incipient trend toward avoidance of the stimulated side on day 1 , which became a significant difference between the start and end of the trial on day 2 (RM-ANOVA, day $\times$ epoch, effect of day: $F_{(2,33)}=5.71, p=0.0074$, effect of day: $F_{(1,33)}=8.67, p=0.0059$; Fig. 10B). In principle, the enhancement of avoidance seen on day 2 could either be a learning effect, in which a specific side preference is retained from day 1 , or a "priming" effect, in which recent prior stimulation sensitizes the real-time avoidant response. However, given the reversal of the stimulated side between days, a choice to avoid the stimulated side on day 2 would result from a learned preference for the chamber stimulated on day 1 . This seems unlikely based on the trend to develop avoidance of the stimulated side over the course of the test on both days. To test for the retention of a learned preference, we performed a 2 day experiment in which one side was stimulated on day 1 and the animals were returned to the shuttle box on day 2 without a light stimulus. No retained side preference was exhibited in the absence of the stimulus (RM-ANOVA, genotype $\times$ day, effect of genotype: $F_{(1,24)}=2.13, p=0.16$, effect of day: $F_{(1,24)}=2.00, p=0.17$; Fig. 

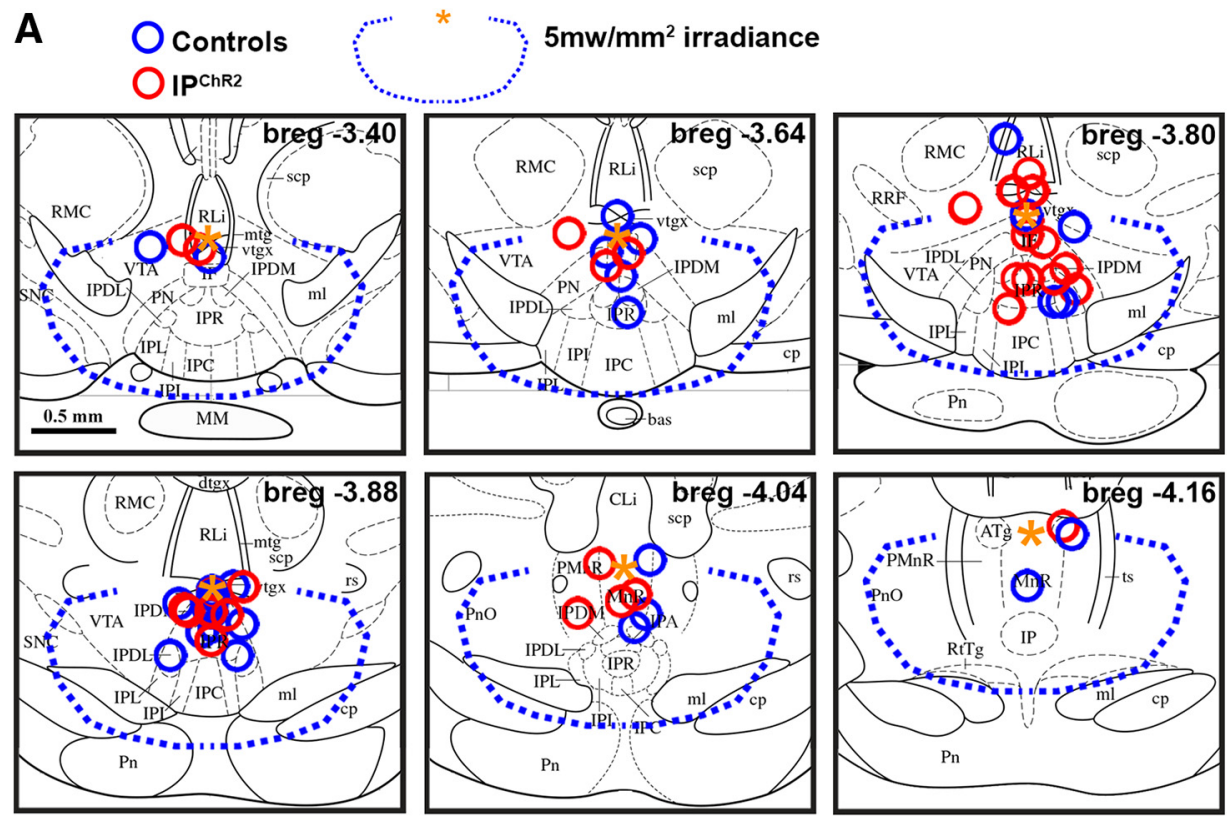

B
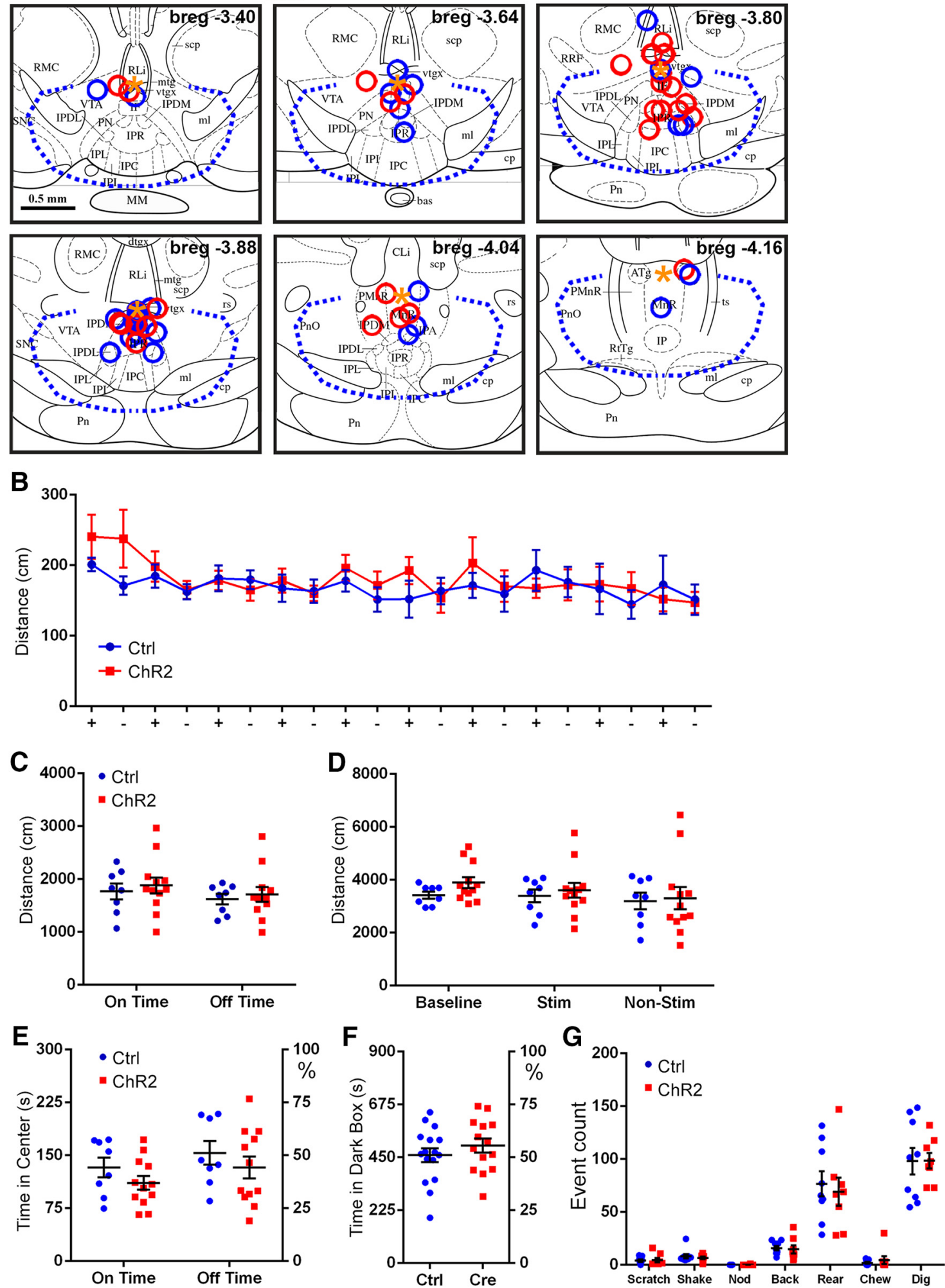
10C). In a second cohort of mice, we tested the reversibility of the avoidance effect. A trend toward avoidance in IP ${ }^{\mathrm{ChR} 2}$ mice on day 2 disappeared by day 10, demonstrating the transient nature of the priming effect $(\mathrm{RM}-\mathrm{ANOVA}$, day $\times$ genotype, effect of genotype: $F_{(1,15)}=3.774, p=0.07$, effect of day: $F_{(2,30)}=0.62$, $p=0.55$; Fig. 10D). Although the trend toward an effect of genotype did not reach statistical significance in this experiment, analysis of day 1 and day 2 data for the combined cohorts showed a clear aversive effect in IP ${ }^{\mathrm{ChR} 2}$ mice on day 2 (RM-ANOVA, day $\times$ genotype, effect of genotype: $F_{(1,35)}=24.86, p<0.0001$, effect of day: $F_{(1,35)}=0.46, p=0.50$; Fig. $\left.10 E, F\right)$. Finally, to eliminate any positive or negative learned effect of side in the primed aversion effect, we provided the initial stimulation in a standard housing cage. Prior stimulation in a separate cage was sufficient to prime the aversive effect $\left(t\right.$ test between genotypes: $t_{(41)}=2.47, p=$ 0.0176; Fig. 10G).

In prior studies, we used an optogenetic ICSS protocol to demonstrate that activation of the dorsal subnucleus of the medial habenula is reinforcing (Hsu et al., 2014, 2016). In this paradigm, mice are given access to paired response wheels, one of which triggers a laser stimulus to the area of interest. After $4 \mathrm{~d}$ of training, the active wheel is switched for four reversal trials. Increased wheel turns, preference for the active wheel after $1-2 \mathrm{~d}$ of training, and reversal of the preference with change of the active wheel are indicative of an ICSS effect. As expected given the aversive nature of IP stimulation in the shuttle box test, IP ${ }^{\mathrm{ChR} 2}$ mice did not show a preference for the stimulus-associated wheel in this paradigm on day 4 or day 8 , when a maximum response would be seen (Fig. 10H). The observed infrequent, sporadic wheel-turning behavior resulted in a very low frequency of light stimulation, which did not demonstrate reinforcement and could not be shown to be aversive because of the low rate of stimulation at baseline.

$\alpha 5$-expressing IP neurons receive input from cholinergic/glutamatergic neurons of the MHbV. The role of cholinergic transmission in this system has not been fully defined, but acetylcholine released at the MHbV-IP interface has the potential to both directly activate IP nicotinic receptors and to act presynaptically to increase glutamate release (Ren et al., 2011; Hsu et al.,

$\leftarrow$

(Figure legend continued.) baseline, stimulation, and poststimulation. The stimulation period consisted of $30 \mathrm{~s}$ periods of $20 \mathrm{~Hz}$ light pulses, alternating with $30 \mathrm{~s}$ periods of lights off. $\boldsymbol{B}$, Distance traveled during 30 s intervals of pulsed light $(+)$ and no light $(-)$ during the stimulation period. Cohort of 12 IP $\mathrm{P}^{\mathrm{ChR} 2}$ and 8 control mice. C, Summary of distance traveled during light on time and light off time during the stimulation period; no effect of light or genotype was observed. $\boldsymbol{D}$, Summary of distance traveled during the baseline, stimulation, and poststimulation periods. No effect of period or genotype was observed. $\boldsymbol{E}$, Time spent in the center of the open-field enclosure during the stimulation period. No effect of light or genotype was observed. $F$, Time spent in the dark chamber of the light/dark box; no effect of light or genotype was observed. Cohort of 14 IP ${ }^{\text {ChR2 }}$ and 16 control mice. G, Somatic signs of nicotine withdrawal. Intermittent pulsed stimulation was delivered to the IP of nicotine-naive IP ChR2 $^{\text {and control }}$ mice (see Materials and Methods) and mice were assessed for six somatic signs of nicotine withdrawal. No effect of genotype was observed. Cohort of $8 \mathbb{I P}^{\mathrm{ChR2}}$ and 9 control mice. Cli, Caudal linear nucleus raphe; MnR, median raphe; PMnR, paramedian raphe; Pn, pons; PnO, pontine reticular nucleus, oral; PN, paranigral nucleus; RLi, rostral linear nucleus raphe; RRF, retrorubral field; $\mathrm{SNc}$, substantia nigra, pars compacta; $\mathrm{SNr}$, substantia nigra, pars reticulata. Scale bar, $0.5 \mathrm{~mm}$. For extended data regarding cannula placement, see Figure 9-1, available at https://doi.org/10.1523/JNEUROSCI.0023-18.2018.f9-1. Pulsed light stimulation induced the expression of CFos in the IP in a pattern similar to that previously obtained with systemic nicotine activation (Ren and Sagar, 1992). For extended data on cFos induction by optogenetic stimulation, see Figure 9-2, available at https://doi.org/10.1523/JNEUROSCI. 0023-18.2018.f9-2.
2013; Frahm et al., 2015). This suggests that, like direct stimulation of the IP, exposure to nicotine could prime the aversive effect of IP activation in RTPP. Nicotine-primed RTPP was performed with a 2 day reversal design. The initial trial and reversal trial were separated by 10 day to avoid the effect of light stimulation priming, which is lost after this amount of time (Fig. 10D). On day 1 , $\mathrm{IP}^{\mathrm{ChR} 2}$ and control mice were given a subcutaneous injection of nicotine $(0.3 \mathrm{mg} / \mathrm{kg}$, see Materials and Methods) and placed a standard housing cage. The chosen dose of nicotine is by itself reinforcing or neutral, not aversive, in place preference assays (Neugebauer et al., 2011; Grieder et al., 2017). Acute locomotion, measured from 1 to 16 min after nicotine administration on day 1 , was reduced compared with that observed in a prior trial in which nicotine was not delivered (RM-ANOVA, drug $\times$ genotype, effect of genotype: $F_{(1,24)}=4.71, p=0.04$, effect of drug: $F_{(1,24)}=46.01, p<0.0001$; Fig. 11A). RTPP was measured $2 \mathrm{~h}$ after nicotine administration. The rapid metabolism of nicotine in mice, with a half-life of $<10 \mathrm{~min}$ (Matta et al., 2007), predicts that the residual blood level from this single dose of nicotine was low at the time of RTPP and is consistent with prior results (Bailey et al., 2010). The acute inhibition of locomotion after nicotine administration had resolved by the time RTPP was conducted. $\mathrm{IP}^{\mathrm{ChR} 2}$ mice exposed subacutely to nicotine in this way showed a marked aversion to IP stimulation (RM-ANOVA, day $\times$ genotype, effect of day: $F_{(1,21)}=0.70, p=0.42$; effect of genotype: $F_{(1,21)}=7.856, p=0.0107$; Fig. $\left.11 B-D\right)$ with a strong reversal of side preference between day 1 and day 10 (Fig. $11 C$ ). In experiments with activity-primed RTPP, the aversive response increased over the $15 \mathrm{~min}$ trial of IP stimulation (RM-ANOVA, day $\times 5$ min epoch, effect of day: $F_{(2,54)}=5.184, p=0.0087$; effect of epoch: $F_{(1,54)}=5.963, p=0.0179$; Fig. $10 B$, whereas in nicotine-primed RTPP, strong aversion was observed in IP ChR2 mice in the first $5 \mathrm{~min}$ period of the trial on day 1 (Fig. 11E). We also noted that, after nicotine administration, control mice showed slight aversion to IP stimulation, spending 40\% fractional time in the laser-paired compartment. This is consistent with the small effect of light seen in control animals in open-field locomotion and was not sufficient to mask the very strong genotype-dependent aversion observed in IP ${ }^{\mathrm{ChR} 2}$ mice.

\section{Discussion}

Smokers self-titrate their nicotine dosage and the propensity to smoke and the intensity of smoking will result from the balance of dose-dependent reinforcement and aversion. Smokers with the $\alpha 5398 \mathrm{~N}$ risk allele, a "mutant" allele in that it is not observed in other species, alter their smoking behavior to deliver more nicotine (Macqueen et al., 2014) and the importance of aversion in this equation is demonstrated by the lower nicotine aversion of these individuals (Jensen et al., 2015). Rodent models strongly implicate the mesolimbic and habenulopeduncular systems in determining the balance of nicotine reinforcement/aversion and resulting drive to consume the drug. Here, we have shown that inward currents elicited by ACh and nicotine are markedly decreased in $\alpha 5^{\mathrm{KO}}$ mice in the IP, but not in the MHbV, and that specific stimulation of the IP neurons that express the $\alpha 5$ receptor can mediate aversion.

\section{Role of the $\alpha 5$ subunit in cellular responses to $\mathrm{ACh}$ and nicotine}

The $\alpha 5$ subunit is an accessory subunit that is not required for pentameric nAChR formation or ligand binding (Zoli et al., 2015; but see Jin et al., 2014 and Jain et al., 2016). In principle, the observed decrease in agonist-elicited currents in $\alpha 5^{\mathrm{KO}}$ mice 

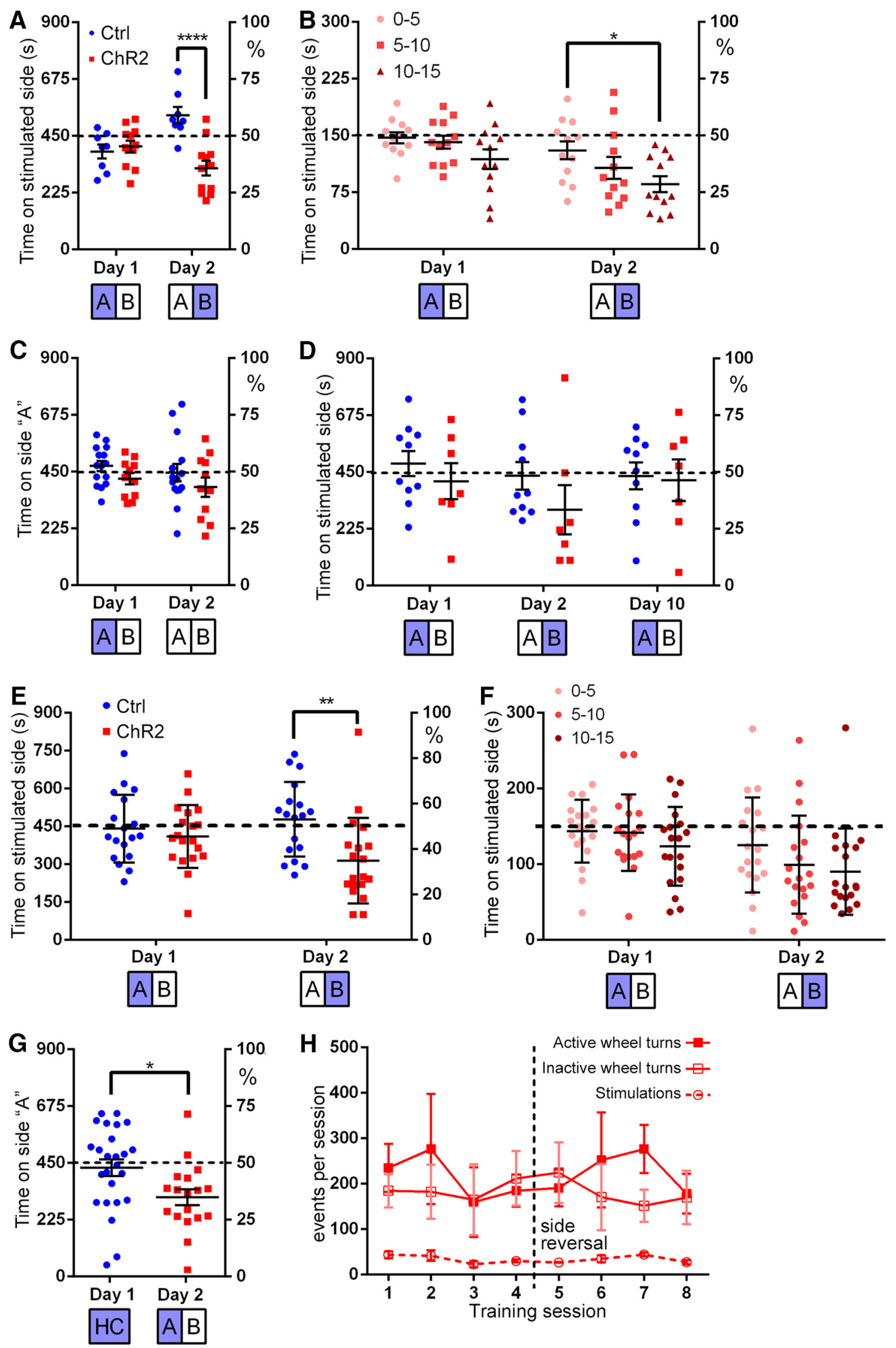

Figure 10. IP stimulation in IP ChR2 mice produces aversion when primed by a recent prior stimulus. Optogenetic stimulation of the IP was performed in a two-compartment shuttle box to elicit RTPP. Video tracking was used to detect the location of the mouse during each 15 min trial and the presence of the animal in one side of the box ("stimulated side") triggered pulses from a $473 \mathrm{~nm}$ laser at $20 \mathrm{~Hz}$. The stimulated side was reversed in each trial and is indicated by blue shading. $\boldsymbol{A}, \mathrm{A} 2 \mathrm{~d}$ reversal trial shows no significant effect of IP stimulation on day 1 , but significant aversion in $\mathrm{IP}^{\mathrm{ChR2}}$ mice on day 2 relative to controls. Note that the control animals have a slight, persisting preference for side B, shown as a negative preference for the stimulated (Figure legend continues.) 
could be due to fewer available receptors, possibly through an effect on stability or trafficking, or because of reduced ion flux per receptor due to altered conductance or channel kinetics. Radioligand binding is unchanged in the IP of $\alpha 5^{\mathrm{KO}}$ mice, as assayed by autoradiography (Baddick and Marks, 2011) and in synaptosomal membrane preparations (Beiranvand et al., 2014), suggesting that receptor levels are unchanged, although in these assays, the abundant nAChRs on MHbV afferents in the IP could obscure a loss of intrinsic binding. However, radioligand binding is also independent of $\alpha 5$ in other CNS regions that express this subunit, such as the VTA and cortical layer 6, and in synaptosome preparations from thalamus, hindbrain, and spinal cord (Jackson et al., 2010). One study using an $\alpha 4$-GFP chimeric subunit as a probe reported reduced $\alpha 4^{*}$ receptor levels in the VTA of $\alpha 5^{\mathrm{KO}}$ mice (Chatterjee et al., 2013), but this is hard to reconcile with the ligand-binding studies. Therefore, it seems likely that most of the decrease in agonist-induced current observed in $\alpha 5^{\mathrm{KO}}$ IP neurons results from reduced channel-specific ion flux rather than fewer available receptors. Direct studies of the effect of the $\alpha 5$ subunit on channel properties have not been performed in CNS neurons. However, incorporation of $\alpha 5$ in $\mathrm{a} 4 \mathrm{~b} 2^{*}$ channels in model cell systems results in increased $\mathrm{Ca}^{2+}$ permeability (Kuryatov et al., 1997; Gerzanich et al., 1998; Tapia et al., 2007) and inclusion of $\alpha 5$ in $\alpha 3 \beta 4^{*}$ channels in autonomic ganglia results in longer channel open times (Ciuraszkiewicz et al., 2013).

Together with other recent reports, these data add to a developing picture of where in the brain the $\alpha 5$ subunit is likely to mediate behavioral responses to nicotine and where it is not. Loss of $\alpha 5$ in mice results in marked decreases in agonist-elected currents in the rostral IP (shown here), prelimbic cortical layer 6 pyramidal neurons (Bailey et al., 2010, 2012; Verhoog et al., 2016), and the VTA (Chatterjee et al., 2013; Morel et al., 2014). We also show a sharp decline in nicotine-elicited action potential

$\leftarrow$

(Figure legend continued.) side on day 1 and a positive preference for the stimulated side on day 2. In contrast, IP ChR2 animals show a shift to specific avoidance of the stimulated side on day 2. ****Post hoc test: multiple-hypothesis-corrected $t$ test of day $2: t_{(36)}=5.21, p<0.0001$. Cohort of $12 \mathrm{IP}^{\mathrm{ChR2}}$ and 8 control mice. $\boldsymbol{B}$, Time course of the development of aversion in IP $\mathrm{P}^{\mathrm{ChR} 2}$ mice. On day 2 a significant difference is observed between the initial and final 5 min epoch. ${ }^{*}$ Post hoc test: multiple-hypothesis-corrected $t$ test $\mathrm{t}_{66}=2.807, p=0.0197$. Cohort of 12 IP $^{\text {ChR2 }}$ mice from $(\boldsymbol{A})$. C, Two-day RTPP trial conducted without stimulation on the second day. No side preference is retained from the first day of the trial. Cohort of 11 I $P^{\text {ChR2 }}$ and 15 control mice. $\boldsymbol{D}$, Reversal of primed aversion. In an extended experiment with three RTPP trials, a trend toward aversion appeared on day 2, but disappeared on day 10 after $8 \mathrm{~d}$ of no stimulation. Cohort of $7 \mathrm{IP}^{\mathrm{ChR2}}$ and 10 control mice. $\boldsymbol{E}$, Combined data for $2 \mathrm{~d}$ side reversal RTPP experiments. RTPP across the $2 \mathrm{~d}$ trial shows development of side aversion in IP $\mathrm{P}^{\mathrm{Ch} 2}$ mice on day 2. The cohort of mice used in $\boldsymbol{A}$ plus the cohort used in Cwere used for the combined analysis, $n=19 \mathrm{IP} \mathrm{P}^{\mathrm{ChR} 2}$ mice and 18 controls. **Post hoc test: $t$ test between genotypes for day $2: \mathrm{t}_{70}=3.43, p=0.002$. $F$, Time course of the acquisition of place aversion for $\mathbb{I}^{\text {ChR2 }}$ mice in the combined cohort in 5 min epochs. $G$, Primed aversion after home cage stimulation. 0 n day 1 , intermittent light pulses were delivered for $15 \mathrm{~min}$ in a standard housing cage in a pseudorandom pattern (see Materials and Methods). RTPP was assessed on day 2 and significant aversion was observed in IPChR2 mice. * Main effect of genotype: $t_{(41)}=2.473, p=0.0176$. Combined cohort of 18 IP ChR2 and 25 control mice. $\boldsymbol{H}, I^{C \text { ChR2 }}$ mice do not respond to ICSS training. Light pulses were delivered in response to turning the active response wheel in a 2-wheel choice paradigm in an $8 \mathrm{~d}$ experiment with reversal of the active response wheel on day 5 . No increase in response rate was observed over time and mice did not develop a preference for the active wheel on day 4 or day 8 of training, when a maximum preference would be expected (RM-ANOVA, day $\times$ wheel for day 4 and $8: F_{(1,8)}=1.45, p=0.26$, effect of wheel: $\left.F_{(1,8)}=0.02, p=0.90\right)$. Wheel turning resulted in a low rate of stimulation that did not change over the course of the experiment. One stimulation (train of light pulses) was delivered per two wheel turn events observed within a specific time interval. The number of stimulations delivered is less than one-half the number of active wheel turns because isolated single wheel turn events were not used to trigger the stimulus (see Materials and Methods). firing frequency in the IPR with the loss of $\alpha 5$. In contrast, we find that mice lacking the $\alpha 5$ subunit show no change in nicotineevoked action potential firing frequency in adult MHbV neurons, consistent with earlier work on nicotine-elicited currents in juvenile mice (Dao et al., 2014). These results correlate strongly with the relative expression of the $\alpha 5 \mathrm{mRNA}$ in these areas (Hsu et al., 2013), pointing to the IP and not the MHb as the site where $\alpha 5$ subunit expression is relevant in the habenulopeduncular system. These results do not support a model in which the behavioral phenotype of $\alpha 5$-null mice (Fowler et al., 2011) or mice overexpressing the $\beta 4$ receptor (Frahm et al., 2011) can be "rescued" or "balanced" by viral expression of the $\alpha 5$ subunit in the habenula.

\section{Role of the IP in behavioral responses to nicotine}

The IP is the interface between the MHb and its output to tegmental systems that may affect motivation and mood states, so it is important to understand the functional circuitry of the IP. Zhao-Shea et al. (2013) have proposed that IPR neurons expressing SST synapse on MHbV afferents, gating the glutamatergic/ cholinergic input to the IP. Application of SST in acute slice preparations has been shown to inhibit EPSCs evoked in IP neurons by the stimulation of $\mathrm{MHb}$ afferents (Ables et al., 2017), but this does not identify the source of SST. The SST neurons in IPR are a subset of the $\alpha 5$-expressing neurons, which are in turn a subset of the GABAergic neurons that are the predominant cell type in the IP (Hsu et al., 2013; Quina et al., 2017). Here, using Cre-mediated tract tracing, we find no evidence that SSTexpressing neurons form a local circuit within the IP to the areas of strongest MHbV input. Instead, the ventral IP subnuclei IPI and IPC receive synaptic input from distinct populations of neurons expressing $\alpha 5$ and SST in the raphe, which are also GABAergic (Hsu et al., 2013). These inputs terminate near MHbV afferents, but whether they synapse upon them or upon the local IP neurons is unknown.

Injection of the nicotinic antagonist mecamylamine into the IP precipitates somatic symptoms of nicotine withdrawal in nicotine-dependent mice (Salas et al., 2009). ACh is an excitatory neurotransmitter at the MHb-IP junction that can either act directly to excite postsynaptic IP neurons or act on MHbV autoreceptors to facilitate glutamate release (Ren et al., 2011; Hsu et al., 2013; Frahm et al., 2015). Therefore, mecamylamine administration probably acts to acutely decrease IP excitability in association with these withdrawal signs. Also consistent with this, inhibition of pacemaker currents in the MHb, which provides excitatory input to the IP, produces withdrawal symptoms (Görlich et al., 2013). Paradoxically, it has been reported that optogenetic stimulation of the IP results in somatic signs of nicotine withdrawal (Zhao-Shea et al., 2013). Here, however, no such signs were detected in $\mathrm{IP}^{\mathrm{ChR} 2}$ mice using an identical stimulation protocol and, because of the nonspecific expression system used, the prior result is potentially explained by off-target effects.

IPR projects prominently to the mesopontine raphe (Quina et al., 2017), suggesting a role in modulating 5HT function. The reduced response of IP neurons to nicotine in $\alpha 5^{\mathrm{KO}}$ mice correlates well with recent studies showing that, in WT mice, nicotine inhibits 5HT neuron firing, whereas in $\alpha 5^{\mathrm{KO}}$ mice, nicotine increases 5HT neuron firing and hippocampal 5HT release (Besson et al., 2016). Loss of $\alpha 5$ function in the IP may thus result in a failure to appropriately brake $5 \mathrm{HT}$ release in response to nicotine. However, the $\alpha 5^{\star}$ GABAergic neurons distributed throughout the MnR could also contribute to these effects (Hsu et al., 2013). 
A

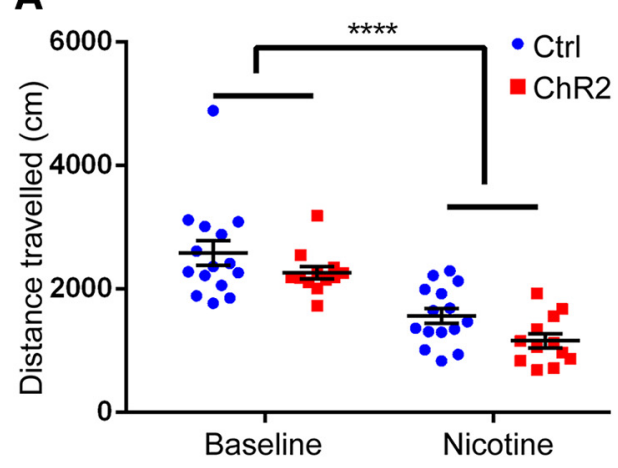

B

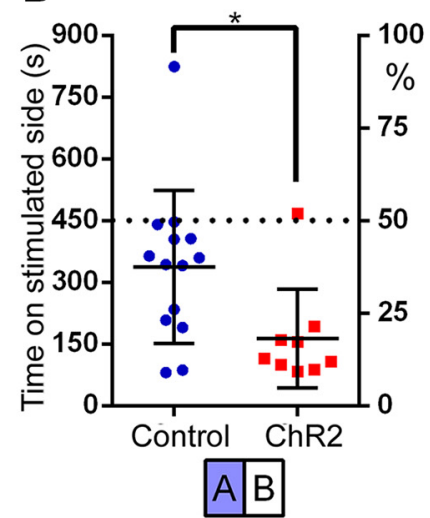

C

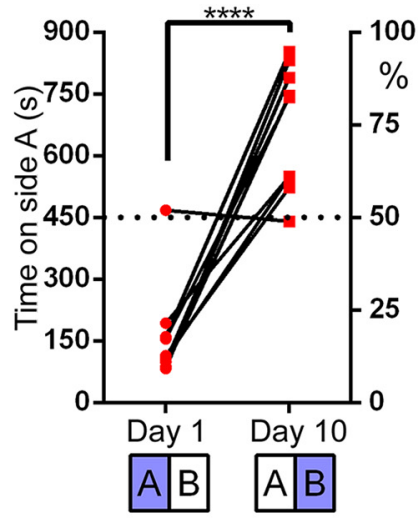

D
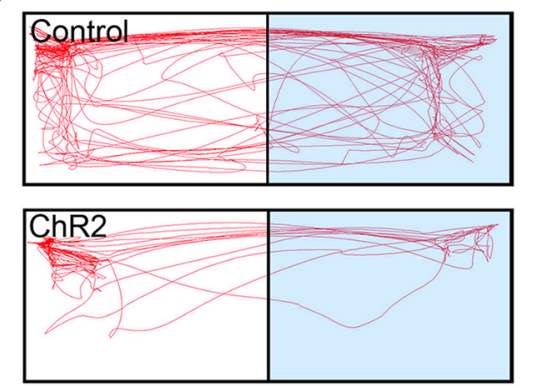

E

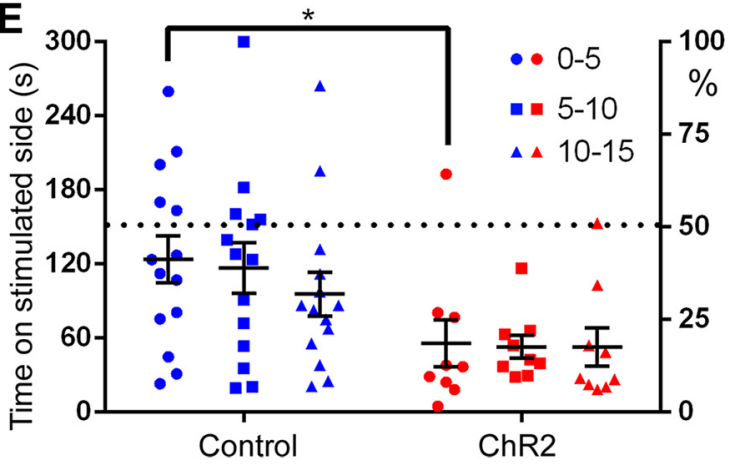

Figure 11. Subacute exposure to a single dose of nicotine primes aversion to IP stimulation in IP ChR2 mice. Nicotine primed aversion was tested in RTPP on day 1 of the experiment and the light-simulated side of the test compartment was reversed on day $10 . A$, Home cage locomotion is suppressed by acute administration of nicotine independent of genotype. IP ${ }^{\text {ChR2 }}$ and control mice were given subcutaneous nicotine injections $(0.3 \mathrm{mg} / \mathrm{kg}$ ) and returned to the home cage for activity monitoring from 1 to $16 \mathrm{~min}$ after administration on day 1 . Baseline activity was measured in the same cohort of mice in a prior trial of home cage locomotion without nicotine. ${ }^{* * *}$ Main effect of drug, $F_{(1,24)}=46.01, p<0.0001$. Cohort of 11 IP ChR2 and 15 control mice. $\boldsymbol{B}-\boldsymbol{E}$, Results of a two-session nicotine-primed RTPP experiment with side reversal on day 10 in a cohort of 9 IP ChR2 and 14 control mice. $\boldsymbol{B}_{\text {, IP }}^{\text {ChR2 }}$ mice treated with nicotine show aversion to IP stimulation on day 1. *Post hoc test: multiple-hypothesis-corrected $t$ test of day 1 effect of genotype: $t_{(42)}=2.325, p=0.05$. C, Comparison of day 1 and day 10 of the reversal experiment shows that IP ${ }^{\text {ChR2 }}$ mice change side preference consistent with nicotine-primed aversion for the light stimulus. ${ }^{* * * *}$ Post hoc test: multiple-hypothesis-corrected $t$ test of Cre effect of day: $t_{(21)}=6.185, p<0.0001 . D$, Examples of the pattern of shuttle box activity in control and ChR2 mice selected from the day 1 results in $\boldsymbol{B}$. The side paired with light stimulation is shaded in blue. $\boldsymbol{E}$, Rapid development of nicotine-primed aversion in the day 1 trial shown in $\boldsymbol{B}$. A significant difference is observed between genotypes in the initial 5 min epoch. ${ }^{*}$ Post hoc test: multiple-hypothesis-corrected $t$ test between genotypes for first 5 min epoch: $t_{(63)}=2.54, p=0.04$.

The role of the MHbV and IP in mediating the propensity to consume nicotine is clearly complex. Here, we have shown that direct, specific stimulation of the IP neurons that receive cholinergic MHbV input can produce aversion, which is greatly enhanced after nicotine administration. Using a self-stimulation paradigm, we could not find any level of IP stimulation that was reinforcing. Nicotinic activation of the MHb may contribute to reinforcement because blockade of $\alpha 3 \beta 4^{\star}$ receptors there inhibits accumbal DA release in response to nicotine (McCallum et al., 2012; Eggan and McCallum, 2016), but this is unlikely to be affected by loss of the $\alpha 5$ subunit because it has no direct effect on the $\mathrm{MHb}$ response to nicotine. Although the MHbV provides excitatory input to the IP, activity of the IP appears to mediate nicotine aversion. Local infusion of nicotine into the IP is not reinforcing (Ikemoto et al., 2006) and silencing of the IP with local anesthetics (Fowler et al., 2011) leads to increased selfadministration of nicotine. The mesolimbic DA system also clearly plays a role in the dose-dependent effects of nicotine on reinforcement and aversion (Exley et al., 2012). These effects are not necessarily paradoxical if viewed along a continuum of nicotine dose-response. In the absence of the $\alpha 5$ subunit, the VTAmediated dose-response curve for reinforcement may be shifted to higher doses of nicotine. IP-mediated aversion may also be attenuated and fail to act as a brake on the consumption of normally aversive higher doses. The loss of $\alpha 5$ activity appears to affect the overall balance of reinforcement and aversion in a way that favors higher consumption in mouse self-administration (Fowler et al., 2011; Morel et al., 2014) and place preference tests (Jackson et al., 2010) and in humans (Macqueen et al., 2014; Jensen et al., 2015). It is this balance of reinforcement and aversion that is likely to be perturbed by the risk alleles of the $\alpha 5$ receptor subunit and contribute to the individual risk for tobacco use.

\section{References}

Ables JL, Gorlich A, Antolin-Fontes B, Wang C, Lipford SM, Riad MH, Ren J, Hu F, Luo M, Kenny PJ, Heintz N, Ibanez-Tallon I (2017) Retrograde inhibition by a specific subset of interpeduncular alpha5 nicotinic neurons regulates nicotine preference. Proc Natl Acad Sci U S A 114:1301213017. CrossRef Medline

Ali T, Renkawitz R, Bartkuhn M (2016) Insulators and domains of gene expression. Curr Opin Genet Dev 37:17-26. CrossRef Medline

Antolin-Fontes B, Ables JL, Görlich A, Ibañez-Tallon I (2015) The habenulo-interpeduncular pathway in nicotine aversion and withdrawal. Neuropharmacology 96:213-222. CrossRef Medline

Baddick CG, Marks MJ (2011) An autoradiographic survey of mouse brain nicotinic acetylcholine receptors defined by null mutants. Biochem Pharmacol 82:828-841. CrossRef Medline

Bailey CD, Alves NC, Nashmi R, De Biasi M, Lambe EK (2012) Nicotinic alpha5 subunits drive developmental changes in the activation and morphology of prefrontal cortex layer VI neurons. Biol Psychiatry 71:120128. CrossRef Medline 
Bailey CD, De Biasi M, Fletcher PJ, Lambe EK (2010) The nicotinic acetylcholine receptor alpha5 subunit plays a key role in attention circuitry and accuracy. J Neurosci 30:9241-9252. CrossRef Medline

Bailey KR, Crawley JN (2009) Anxiety-related behaviors in mice. In: Methods of behavior analysis in neuroscience (Buccafusco JJ, ed). Boca Raton, FL: CRC Press/Taylor \& Francis.

Barrie ES, Hartmann K, Lee SH, Frater JT, Seweryn M, Wang D, Sadee W (2017) The CHRNA5/CHRNA3/CHRNB4 nicotinic receptor regulome: genomic architecture, regulatory variants, and clinical associations. Hum Mutat 38:112-119. CrossRef Medline

Beiranvand F, Zlabinger C, Orr-Urtreger A, Ristl R, Huck S, Scholze P (2014) Nicotinic acetylcholine receptors control acetylcholine and noradrenaline release in the rodent habenulo-interpeduncular complex. Br J Pharmacol 171:5209-5224. CrossRef Medline

Berrettini WH, Doyle GA (2012) The CHRNA5-A3-B4 gene cluster in nicotine addiction. Mol Psychiatry 17:856-866. CrossRef Medline

Besson M, Guiducci S, Granon S, Guilloux JP, Guiard B, Reperant C, Faure P, Pons S, Cannazza G, Zoli M, Gardier AM, Maskos U (2016) Alterations in alpha5* nicotinic acetylcholine receptors result in midbrain- and hippocampus-dependent behavioural and neural impairments. Psychopharmacology (Berl) 233:3297-3314. CrossRef Medline

Broms J, Antolin-Fontes B, Tingström A, Ibañez-Tallon I (2015) Conserved expression of the GPR151 receptor in habenular axonal projections of vertebrates. J Comp Neurol 523:359-380. CrossRef Medline

Chatterjee S, Santos N, Holgate J, Haass-Koffler CL, Hopf FW, Kharazia V, Lester H, Bonci A, Bartlett SE (2013) The alpha5 subunit regulates the expression and function of alpha $4^{*}$-containing neuronal nicotinic acetylcholine receptors in the ventral-tegmental area. PLoS One 8:e68300. CrossRef Medline

Ciuraszkiewicz A, Schreibmayer W, Platzer D, Orr-Urtreger A, Scholze P, Huck S (2013) Single-channel properties of alpha3beta4, alpha3beta4alpha5 and alpha3beta4beta2 nicotinic acetylcholine receptors in mice lacking specific nicotinic acetylcholine receptor subunits. J Physiol 591:32713288. CrossRef Medline

Dao DQ, Perez EE, Teng Y, Dani JA, De Biasi M (2014) Nicotine enhances excitability of medial habenular neurons via facilitation of neurokinin signaling. J Neurosci 34:4273-4284. CrossRef Medline

Eggan BL, McCallum SE (2016) 18-methoxycoronaridine acts in the medial habenula to attenuate behavioral and neurochemical sensitization to nicotine. Behav Brain Res 307:186-193. CrossRef Medline

Exley R, McIntosh JM, Marks MJ, Maskos U, Cragg SJ (2012) Striatal alpha5 nicotinic receptor subunit regulates dopamine transmission in dorsal striatum. J Neurosci 32:2352-2356. CrossRef Medline

Fowler CD, Kenny PJ (2014) Nicotine aversion: Neurobiological mechanisms and relevance to tobacco dependence vulnerability. Neuropharmacology 76:533-544. CrossRef Medline

Fowler CD, Lu Q, Johnson PM, Marks MJ, Kenny PJ (2011) Habenular alpha5 nicotinic receptor subunit signalling controls nicotine intake. Nature 471:597-601. CrossRef Medline

Frahm S, Antolin-Fontes B, Görlich A, Zander JF, Ahnert-Hilger G, IbañezTallon I (2015) An essential role of acetylcholine-glutamate synergy at habenular synapses in nicotine dependence. eLife 4:e11396. CrossRef Medline

Frahm S, Slimak MA, Ferrarese L, Santos-Torres J, Antolin-Fontes B, Auer S, Filkin S, Pons S, Fontaine JF, Tsetlin V, Maskos U, Ibañez-Tallon I (2011) Aversion to nicotine is regulated by the balanced activity of beta 4 and alpha5 nicotinic receptor subunits in the medial habenula. Neuron 70 : 522-535. CrossRef Medline

Franceschini D, Paylor R, Broide R, Salas R, Bassetto L, Gotti C, De Biasi M (2002) Absence of alpha7-containing neuronal nicotinic acetylcholine receptors does not prevent nicotine-induced seizures. Brain Res Mol Brain Res 98:29-40. CrossRef Medline

George AA, Lucero LM, Damaj MI, Lukas RJ, Chen X, Whiteaker P (2012) Function of human alpha3beta4alpha5 nicotinic acetylcholine receptors is reduced by the alpha5(D398N) variant. J Biol Chem 287:25151-25162. CrossRef Medline

Gerfen CR, Paletzki R, Heintz N (2013) GENSAT BAC cre-recombinase driver lines to study the functional organization of cerebral cortical and basal ganglia circuits. Neuron 80:1368-1383. CrossRef Medline

Gerzanich V, Wang F, Kuryatov A, Lindstrom J (1998) alpha 5 subunit alters desensitization, pharmacology, $\mathrm{Ca}++$ permeability and $\mathrm{Ca}++$ modula- tion of human neuronal alpha 3 nicotinic receptors. J Pharmacol Exp Ther 286:311-320. Medline

Gong S, Zheng C, Doughty ML, Losos K, Didkovsky N, Schambra UB, Nowak NJ, Joyner A, Leblanc G, Hatten ME, Heintz N (2003) A gene expression atlas of the central nervous system based on bacterial artificial chromosomes. Nature 425:917-925. CrossRef Medline

Görlich A, Antolin-Fontes B, Ables JL, Frahm S, Slimak MA, Dougherty JD, Ibañez-Tallon I (2013) Reexposure to nicotine during withdrawal increases the pacemaking activity of cholinergic habenular neurons. Proc Natl Acad Sci U S A 110:17077-17082. CrossRef Medline

Grieder TE, George O, Yee M, Bergamini MA, Chwalek M, Maal-Bared G, Vargas-Perez H, van der Kooy D (2017) Deletion of alpha5 nicotine receptor subunits abolishes nicotinic aversive motivational effects in a manner that phenocopies dopamine receptor antagonism. Eur J Neurosci 46:1673-1681. CrossRef Medline

Harrington L, Viñals X, Herrera-Solís A, Flores A, Morel C, Tolu S, Faure P, Maldonado R, Maskos U, Robledo P (2016) Role of beta $4^{*}$ nicotinic acetylcholine receptors in the habenulo-interpeduncular pathway in nicotine reinforcement in mice. Neuropsychopharmacology 41:1790-1802. CrossRef Medline

Harris JA, Wook Oh S, Zeng H (2012) Adeno-associated viral vectors for anterograde axonal tracing with fluorescent proteins in nontransgenic and cre driver mice. Curr Protoc Neurosci Chapter 1:Unit 1.20.1-18. CrossRef Medline

Hsu YW, Tempest L, Quina LA, Wei AD, Zeng H, Turner EE (2013) Medial habenula output circuit mediated by alpha5 nicotinic receptor-expressing GABAergic neurons in the interpeduncular nucleus. J Neurosci 33: 18022-18035. CrossRef Medline

Hsu YW, Wang SD, Wang S, Morton G, Zariwala HA, de la Iglesia HO, Turner EE (2014) Role of the dorsal medial habenula in the regulation of voluntary activity, motor function, hedonic state, and primary reinforcement. J Neurosci 34:11366-11384. CrossRef Medline

Hsu YW, Morton G, Guy EG, Wang SD, Turner EE (2016) Dorsal medial habenula regulation of mood-related behaviors and primary reinforcement by tachykinin-expressing habenula neurons. eNeuro 3: pii: ENEURO.0109-16.2016. CrossRef Medline

Ikemoto S, Qin M, Liu ZH (2006) Primary reinforcing effects of nicotine are triggered from multiple regions both inside and outside the ventral tegmental area. J Neurosci 26:723-730. CrossRef Medline

Jackson KJ, Martin BR, Changeux JP, Damaj MI (2008) Differential role of nicotinic acetylcholine receptor subunits in physical and affective nicotine withdrawal signs. J Pharmacol Exp Ther 325:302-312. CrossRef Medline

Jackson KJ, Marks MJ, Vann RE, Chen X, Gamage TF, Warner JA, Damaj MI (2010) Role of alpha5 nicotinic acetylcholine receptors in pharmacological and behavioral effects of nicotine in mice. J Pharmacol Exp Ther 334:137-146. CrossRef Medline

Jain A, Kuryatov A, Wang J, Kamenecka TM, Lindstrom J (2016) Unorthodox acetylcholine binding sites formed by alpha5 and beta3 accessory subunits in alpha4beta $2^{\star}$ nicotinic acetylcholine receptors. J Biol Chem 291:23452-23463. CrossRef Medline

Jensen KP, DeVito EE, Herman AI, Valentine GW, Gelernter J, Sofuoglu M (2015) A CHRNA5 smoking risk variant decreases the aversive effects of nicotine in humans. Neuropsychopharmacology 40:2813-2821. CrossRef Medline

Jin X, Bermudez I, Steinbach JH (2014) The nicotinic alpha5 subunit can replace either an acetylcholine-binding or nonbinding subunit in the alpha4beta2* neuronal nicotinic receptor. Mol Pharmacol 85:11-17. CrossRef Medline

Koukouli F, Rooy M, Tziotis D, Sailor KA, O’Neill HC, Levenga J, Witte M, Nilges M, Changeux JP, Hoeffer CA, Stitzel JA, Gutkin BS, DiGregorio DA, Maskos U (2017) Nicotine reverses hypofrontality in animal models of addiction and schizophrenia. Nat Med 23:347-354. CrossRef Medline

Kuryatov A, Berrettini W, Lindstrom J (2011) Acetylcholine receptor (AChR) alpha5 subunit variant associated with risk for nicotine dependence and lung cancer reduces (alpha4beta2)(2)alpha5 AChR function. Mol Pharmacol 79:119-125. CrossRef Medline

Kuryatov A, Gerzanich V, Nelson M, Olale F, Lindstrom J (1997) Mutation causing autosomal dominant nocturnal frontal lobe epilepsy alters $\mathrm{Ca} 2+$ permeability, conductance, and gating of human alpha4beta2 nicotinic acetylcholine receptors. J Neurosci 17:9035-9047. CrossRef Medline 
Lassi G, Taylor AE, Timpson NJ, Kenny PJ, Mather RJ, Eisen T, Munafò MR (2016) The CHRNA5-A3-B4 gene cluster and smoking: from discovery to therapeutics. Trends Neurosci 39:851-861. CrossRef Medline

Lima LB, Bueno D, Leite F, Souza S, Gonçalves L, Furigo IC, Donato J Jr, Metzger M (2017) Afferent and efferent connections of the interpeduncular nucleus with special reference to circuits involving the habenula and raphe nuclei. J Comp Neurol 525:2411-2442. CrossRef Medline

Macqueen DA, Heckman BW, Blank MD, Janse Van Rensburg K, Park JY, Drobes DJ, Evans DE (2014) Variation in the alpha 5 nicotinic acetylcholine receptor subunit gene predicts cigarette smoking intensity as a function of nicotine content. Pharmacogenomics J 14:70-76. CrossRef Medline

Madisen L, Mao T, Koch H, Zhuo JM, Berenyi A, Fujisawa S, Hsu YW, Garcia AJ 3rd, Gu X, Zanella S, Kidney J, Gu H, Mao Y, Hooks BM, Boyden ES, Buzsáki G, Ramirez JM, Jones AR, Svoboda K, Han X, et al. (2012) A toolbox of cre-dependent optogenetic transgenic mice for light-induced activation and silencing. Nat Neurosci 15:793-802. CrossRef Medline

Madisen L, Zwingman TA, Sunkin SM, Oh SW, Zariwala HA, Gu H, Ng LL, Palmiter RD, Hawrylycz MJ, Jones AR, Lein ES, Zeng H (2010) A robust and high-throughput cre reporting and characterization system for the whole mouse brain. Nat Neurosci 13:133-140. CrossRef Medline

Marks MJ, Pauly JR, Gross SD, Deneris ES, Hermans-Borgmeyer I, Heinemann SF, Collins AC (1992) Nicotine binding and nicotinic receptor subunit RNA after chronic nicotine treatment. J Neurosci 12:2765-2784. CrossRef Medline

Matta SG, Balfour DJ, Benowitz NL, Boyd RT, Buccafusco JJ, Caggiula AR, Craig CR, Collins AC, Damaj MI, Donny EC, Gardiner PS, Grady SR, Heberlein U, Leonard SS, Levin ED, Lukas RJ, Markou A, Marks MJ, McCallum SE, Parameswaran N, et al. (2007) Guidelines on nicotine dose selection for in vivo research. Psychopharmacology (Berl) 190:269319. CrossRef Medline

McCallum SE, Cowe MA, Lewis SW, Glick SD (2012) alpha3beta4 nicotinic acetylcholine receptors in the medial habenula modulate the mesolimbic dopaminergic response to acute nicotine in vivo. Neuropharmacology 63:434-440. CrossRef Medline

Morel C, Fattore L, Pons S, Hay YA, Marti F, Lambolez B, De Biasi M, Lathrop M, Fratta W, Maskos U, Faure P (2014) Nicotine consumption is regulated by a human polymorphism in dopamine neurons. Mol Psychiatry 19:930-936. CrossRef Medline

Neugebauer NM, Henehan RM, Hales CA, Picciotto MR (2011) Mice lacking the galanin gene show decreased sensitivity to nicotine conditioned place preference. Pharmacol Biochem Behav 98:87-93. CrossRef Medline

Oh SW, Harris JA, Ng L, Winslow B, Cain N, Mihalas S, Wang Q, Lau C, Kuan L, Henry AM, Mortrud MT, Ouellette B, Nguyen TN, Sorensen SA, Slaughterbeck CR, Wakeman W, Li Y, Feng D, Ho A, Nicholas E, et al. (2014) A mesoscale connectome of the mouse brain. Nature 508:207214. CrossRef Medline

Paxinos G, Franklin KBJ (2001) The mouse brain in stereotaxic coordinates, Ed 2. San Diego, CA: Academic.

Picciotto MR, Mineur YS (2014) Molecules and circuits involved in nicotine addiction: the many faces of smoking. Neuropharmacology 76:545-553. CrossRef Medline

Quina LA, Harris J, Zeng H, Turner EE (2017) Specific connections of the interpeduncular subnuclei reveal distinct components of the habenulopeduncular pathway. J Comp Neurol 525:2632-2656. CrossRef Medline

Ren J, Qin C, Hu F, Tan J, Qiu L, Zhao S, Feng G, Luo M (2011) Habenula "cholinergic" neurons corelease glutamate and acetylcholine and activate postsynaptic neurons via distinct transmission modes. Neuron 69:445452. CrossRef Medline

Ren T, Sagar SM (1992) Induction of c-fos immunostaining in the rat brain after the systemic administration of nicotine. Brain Res Bull 29:589-597. CrossRef Medline

Rose JE, Mukhin AG, Lokitz SJ, Turkington TG, Herskovic J, Behm FM, Garg S, Garg PK (2010) Kinetics of brain nicotine accumulation in dependent and nondependent smokers assessed with PET and cigarettes containing
11C-nicotine. Proc Natl Acad Sci U S A 107:5190-5195. CrossRef Medline

Salas R, Orr-Urtreger A, Broide RS, Beaudet A, Paylor R, De Biasi M (2003) The nicotinic acetylcholine receptor subunit alpha 5 mediates short-term effects of nicotine in vivo. Mol Pharmacol 63:1059-1066. CrossRef Medline

Salas R, Sturm R, Boulter J, De Biasi M (2009) Nicotinic receptors in the habenulo-interpeduncular system are necessary for nicotine withdrawal in mice. J Neurosci 29:3014-3018. CrossRef Medline

Sciaccaluga M, Moriconi C, Martinello K, Catalano M, Bermudez I, Stitzel JA, Maskos U, Fucile S (2015) Crucial role of nicotinic alpha5 subunit variants for Ca2 + fluxes in ventral midbrain neurons. FASEB J 29:3389 3398. CrossRef Medline

Shih PY, Engle SE, Oh G, Deshpande P, Puskar NL, Lester HA, Drenan RM (2014) Differential expression and function of nicotinic acetylcholine receptors in subdivisions of medial habenula. J Neurosci 34:9789-9802. CrossRef Medline

Siu EC, Tyndale RF (2007) Characterization and comparison of nicotine and cotinine metabolism in vitro and in vivo in $\mathrm{DBA} / 2$ and $\mathrm{C} 57 \mathrm{BL} / 6$ mice. Mol Pharmacol 71:826-834. CrossRef Medline

Smith RM, Alachkar H, Papp AC, Wang D, Mash DC, Wang JC, Bierut LJ, Sadee W (2011) Nicotinic alpha5 receptor subunit mRNA expression is associated with distant $5^{\prime}$ upstream polymorphisms. Eur J Hum Genet 19:76-83. CrossRef Medline

Tamamaki N, Yanagawa Y, Tomioka R, Miyazaki J, Obata K, Kaneko T (2003) Green fluorescent protein expression and colocalization with calretinin, parvalbumin, and somatostatin in the GAD67-GFP knock-in mouse. J Comp Neurol 467:60-79. CrossRef Medline

Tammimäki A, Herder P, Li P, Esch C, Laughlin JR, Akk G, Stitzel JA (2012) Impact of human D398N single nucleotide polymorphism on intracellular calcium response mediated by alpha3beta4alpha5 nicotinic acetylcholine receptors. Neuropharmacology 63:1002-1011. CrossRef Medline

Taniguchi H, He M, Wu P, Kim S, Paik R, Sugino K, Kvitsani D, Fu Y, Lu J, Lin Y, Miyoshi G, Shima Y, Fishell G, Nelson SB, Huang ZJ (2011) A resource of cre driver lines for genetic targeting of GABAergic neurons in cerebral cortex. Neuron 71:995-1013. CrossRef Medline

Tapia L, Kuryatov A, Lindstrom J (2007) Ca2+ permeability of the (alpha4)3(beta2)2 stoichiometry greatly exceeds that of (alpha4)2(beta2)3 human acetylcholine receptors. Mol Pharmacol 71:769-776. CrossRef Medline

Verhoog MB, Obermayer J, Kortleven CA, Wilbers R, Wester J, Baayen JC, De Kock CP, Meredith RM, Mansvelder HD (2016) Layer-specific cholinergic control of human and mouse cortical synaptic plasticity. Nat Commun 7:12826. CrossRef Medline

Wada E, McKinnon D, Heinemann S, Patrick J, Swanson LW (1990) The distribution of mRNA encoded by a new member of the neuronal nicotinic acetylcholine receptor gene family (alpha 5) in the rat central nervous system. Brain Res 526:45-53. CrossRef Medline

Winzer-Serhan UH, Leslie FM (1997) Codistribution of nicotinic acetylcholine receptor subunit alpha3 and beta4 mRNAs during rat brain development. J Comp Neurol 386:540-554. CrossRef Medline

Zhao S, Ting JT, Atallah HE, Qiu L, Tan J, Gloss B, Augustine GJ, Deisseroth K, Luo M, Graybiel AM, Feng G (2011) Cell type-specific channelrhodopsin-2 transgenic mice for optogenetic dissection of neural circuitry function. Nat Methods 8:745-752. CrossRef Medline

Zhao-Shea R, Liu L, Pang X, Gardner PD, Tapper AR (2013) Activation of GABAergic neurons in the interpeduncular nucleus triggers physical nicotine withdrawal symptoms. Curr Biol 23:2327-2335. CrossRef Medline

Zhao-Shea R, DeGroot SR, Liu L, Vallaster M, Pang X, Su Q, Gao G, Rando OJ, Martin GE, George O, Gardner PD, Tapper AR (2015) Increased CRF signalling in a ventral tegmental area-interpeduncular nucleusmedial habenula circuit induces anxiety during nicotine withdrawal. Nat Commun 6:6770. CrossRef Medline

Zoli M, Pistillo F, Gotti C (2015) Diversity of native nicotinic receptor subtypes in mammalian brain. Neuropharmacology 96:302-311. CrossRef Medline 